\title{
Experimental and numerical study on the relationship between water imbibition and salt ion diffusion in fractured shale reservoirs
}

\author{
Liu Yang a, b, c, *, Hongkui Ge ${ }^{\text {b }}$, Xian Shi ${ }^{\text {d, }}{ }^{* *}$, Jing Li ${ }^{\text {b }}$, Tong Zhou ${ }^{\text {b }}$, Wenke Cao ${ }^{\text {b }}$, \\ Kunheng Zhang ${ }^{\mathrm{e}}$, Yanjun Zhang ${ }^{\mathrm{b}}$, Meng Gao ${ }^{\mathrm{b}}$ \\ a State Key Laboratory of Shale Oil and Gas Enrichment Mechanisms and Effective Development, Beijing, 100083, China \\ b State Key Laboratory of Petroleum Resources and Prospecting, China University of Petroleum, Beijing 102249, China \\ ${ }^{c}$ Key Laboratory for Mechanics in Fluid Solid Coupling Systems, Institute of Mechanics, Chinese Academy of Sciences, 100190 Beijing, China \\ d School of Petroleum Engineering, China University of Petroleum (East China), Qingdao 266580, China \\ e School of Foreign Languages, China University of Petroleum, Beijing 102249, China
}

\section{A R T I C L E I N F O}

\section{Article history:}

Received 23 August 2016

Received in revised form

5 December 2016

Accepted 13 December 2016

Available online 22 December 2016

\section{Keywords:}

Imbibition

Ion diffusion

Shale

Capillary pressure

Fracturing

\begin{abstract}
A B S T R A C T
Field observations demonstrate that shale gas wells feature a low flowback efficiency $(<30 \%)$ and highsalinity flowback water (approximately $200 \mathrm{kppm}$ ) after multistage hydraulic fracturing operations. The water recovery and salinity profile could be regarded as a critical method for volumetric and chemical analyses to characterize the reservoir properties and complexity of the fractured network. This paper aims to understand the relationship between fracturing imbibition and ion diffusion, which are responsible for inefficient water recovery and high-salinity flowback fluid, respectively. Comparative imbibition experiments are performed on different shale and sandstone samples, and an electrical conductivity meter is used to monitor the change in ion concentration change of the imbibition fluid. A mathematical model based on theoretical analysis is proposed to clarify the correlation between imbibition and ion diffusion. Both the experimental and analytical solution results show that the imbibition fluid conductivity resulting from ion diffusion is proportional to the square root of time, which is similar to the law of capillary-driven imbibition into porous media. Water imbibition into gas shale and ion diffusion into water proceed simultaneously in the opposite direction, and only the imbibition front contacting the pore wall with salt ions can cause the salt ions to dissolve and diffuse into water. The analytical solution results also indicate that the effects of the porosity, surface tension, contacting area and wetting angle on the water imbibition rate are in consistent with that of the ion diffusion rate. The permeability, however, shows a positive correlation with the imbibition rate and a negative correlation with the ion diffusion rate. The initial water saturation is negatively related to the imbibition rate, and positively related to the ion diffusion rate. In addition, smectite and $\mathrm{I} / \mathrm{S}$ could enhance the imbibition and diffusion rates. It is observed that illite concentration has no relationship with the imbibition and diffusion rates, indicating that illite minerals do not significantly affect the imbibition/diffusion rate in these clay-rich shales. This research contributes to understanding the correlation between imbibition and ion diffusion, which is significant for flow-back analysis after fracturing operations.
\end{abstract}

() 2016 Elsevier B.V. All rights reserved.

\section{Introduction}

Multistage fracturing is a key technology for the economic exploration of shale gas (Novlesky et al., 2011). After a large volume

\footnotetext{
* Corresponding author. State Key Laboratory of Petroleum Resources and Prospecting, China University of Petroleum, Beijing, 102249, China.

** Corresponding author.

E-mail address: shidayangliu@126.com (L. Yang).
}

of slick water is injected into a shale formation, the flowback efficiency is generally lower than $30 \%$, and even lower than $5 \%$ in the Haynesville shale reservoir (Penny et al., 2006; King, 2012). Meanwhile, the concentration of salt ions in flowback water increases with time (Ghanbari and Dehghanpour). The salinity in shale gas wells reaches 200kppm in the Horn River Basin (Blaunch et al., 2009; Pritz and Kirby, 2011). The volumetric analysis based on flowback efficiency and chemical analysis based on the salinity of flowback water are of great significance to understanding the 
reservoir properties and evaluating the characteristics of artificial fracture networks.

Recent studies show that the fracturing fluid imbibition into the shale matrix is the key reason for low flowback efficiency. Published studies have focused on the fracturing fluid imbibition mechanism in gas shale. The driving force of imbibition in a conventional reservoir is capillary pressure, while both capillary pressure and osmotic pressure could drive the water into the shale matrix (Dehghanpour et al., 2013; Yang et al., 2016). In clay-rich shale, the osmotic pressure is more powerful than the capillary pressure, and the water volume imbibed into the matrix therefore significantly surpasses the pore volume measured by gas (Ge et al., 2015). Moreover, the intense imbibition effect in gas shale can enhance the pore pressure and then induce the generation of tensile fractures (Yang et al., 2015; Junjian and Sheik, 2015). The pore structure in shale is more complicated than that in conventional sandstone, which causes the special imbibition characteristics in gas shale. As for the dual-porosity nature of shale, shale exhibits a distinct transition from a higher imbibition rate to a lower imbibition rate (Roychaudhuri et al., 2013). The low imbibition rate suggests that the matrix reflects a relatively low pore connectivity depicted by the slope in the curve [log (cumulative imbibition) vs. log (imbibition time)]. Hu et al. (2012) proposed that the matrix in Barnett shale presents imbibition behavior of 0.26 , indicating the low pore connectivity.

Some studies concluded that the salt concentration in flowback water is related to the diffusion of salt ions into the injected water (Haluszczak et al., 2013; Ghanbari and Dehghanpour, 2015). Keller and Liovando (1989) proposed that the electrical conductivity of the produced water increases with time, demonstrating that salt ions of shale dissolve and diffuse into water. The ion diffusion rate in the direction parallel to the bedding plane is faster than that vertical to the bedding plane (Ghanbari et al., 2013). In addition, clay minerals have a great influence on ion diffusion. The charged clay interlayers have the property of a semipermeable membrane, which cannot restrict water molecule movement but does restrict ion movement (Mitchell and Moench, 1993). Many researchers argued that the ion diffusion into water follows Fick's diffusion law (Treybal, 1980; Ghanbari and Dehghanpour, 2015). Nevertheless, Knudsen's diffusion law rather than Fick's diffusion law may be more reliable for ion diffusion in nanopores of gas shale as Fick's law cannot well explain the collision between the ions and the nanopore walls.

The physical and chemical flowback data could be used to characterize the reservoir and artificial fracture network. Fan et al. (2010) stated that a more complex fracture network could result in lower water recovery. As the important indicator for distinguishing the formation water and fracturing fluid, the ion content and type in flowback water should be given much attention (Asadi et al., 2008). The chemical signature in the water recovered from induced fractures is different from that recovered from reactivated secondary fractures (Bearinger, 2013). In addition, the architecture of the induced fracture network has effects on the shape of salt concentration profiles during the flowback operations, and the concentration of dissolved salt is positively related to the surface area of the fracture network.

As for the investigations into the relationship between imbibition and ion diffusion, Ballard et al. (1994) and Zolfaghari et al. (2014) proposed that the ion diffusion rate is similar to the imbibition rate, depending on permeability, porosity, clay content and contact surface area. Ghanbari et al. (2013) conducted imbibition/diffusion experiments and found that the behaviors of imbibition curves are well correlated to that of diffusion curves. In spite of these recent studies, two major questions still remain: (1) What is the reason for the similar behaviors of imbibition and diffusion curves? (2) How do we set up the mathematical model for the quantitative interpretation of the imbibition/diffusion relationship? The aim of this paper is to extend the previous investigations and answer these questions.

\section{Experiments}

\subsection{Materials}

The shale samples are selected from typical shale formations in China, and the conventional sandstone reservoir samples are collected for comparison. The geological information of different formations can be found in Table 1. It should be noted that the shale formations (i.e., Lujiaping, Longmaxi, Niutitang and Xujiahe formation) in China's Sichuan Basin have the greatest potential for shale gas production. In particular, a large number of breakthroughs along the path to commercial exploitation have been realized. The Ganchaigou formation of Qaidam Basin, known to be clay-rich, is provided as a calibration standard.

The average mineralogy content of the formations is shown in Table 2. The mineral compositions are obtained by D/MAX 2500X X-ray diffractometer following the testing standard of SY/T51632010. The measurement temperature and relative humility are $20{ }^{\circ} \mathrm{C}$ and $40 \%$. The minerals of the shale formations are characterized by high content of smectite $+\mathrm{I} / \mathrm{S}$ (14-33\%) and quartz (36-55\%). The total concentration of clay minerals ranges from $23.7 \%$ to $55 \%$. In addition, the total concentration of clay in continental environment shale is much larger than that in marine shale (Ji et al., 2014).

Pictures of the samples are shown in Fig. 1. It is demonstrated that the shale is black and gray and composed of small particles that are obviously different from sandstone. Twelve samples are used to conduct comparative imbibition/diffusion experiments. The physical parameters of the samples are shown in Table 3. Due to the different brittleness of the core materials, not all the samples can be drilled into cylindrical plugs. Some samples must be machined into rectangular blocks by cutting. In addition, one-end-open (OEO), two-ends-open (TEO) and all-faces-open (AFO) are common boundary conditions for imbibition experiments (Kim and Kovscek, 2014). OEO means that only one end face is open for imbibition and epoxy is used to keep other faces impermeable. OEO and TEO are obtained to conduct one-dimensional imbibition experiments. The fluid used in the experiments is distilled water with an electrical conductivity of $2.3 \mathrm{uS} / \mathrm{cm}$. The fracturing fluid adopted during the multistage fracturing operations is slick water, which contains a small amount of friction reducing agents. Therefore, the adoption of distilled water is able to meet the application requirements.

\subsection{Experimental procedure}

Spontaneous imbibition refers to the process by which water is imbibed into shale spontaneously under the joint actions of capillary pressure and clay osmotic pressure (Dehghanpour et al., 2013). Because of the relatively low imbibition volume in shale, a higher accurate analytical balance is adopted to measure the shale mass variation, which is the Mettler XPE205 analytical balance with a precision of $0.00001 \mathrm{~g}$ (Fig. 2(a)). Ion diffusion refers to the process by which salt ions in shale matrix pores diffuse into water under the influence of concentration differences. As the concentration of total dissolved solids increases, the electrical conductivity of water rises linearly $(1 \mathrm{mg} / \mathrm{L}=2 \mathrm{uS} / \mathrm{cm})$. The ion diffusion can be evaluated by the conductivity meter. The Mettler Toledo S470 electrical conductivity meter is used in this study. The accuracy is $0.1 \mu \mathrm{S} / \mathrm{cm}$, and the measurement range is $2000 \mathrm{~ms} / \mathrm{cm}$.

The test procedure for imbibition/diffusion experiments 
Table 1

Tight reservoir properties in this study.

\begin{tabular}{|c|c|c|c|c|c|}
\hline Label & Formation & Lithology & Source & Depositional environment & Geological age \\
\hline LJP & Lujiaping & Shale & Sichuan Basin & Marine & Lower Cambrian \\
\hline LMX & Longmaxi & Shale & Sichuan Basin & Marine & Lower Silurian \\
\hline NTT & Niutitang & Shale & Sichuan Basin & Marine & Lower Cambrian \\
\hline $\mathrm{XJH}$ & Xujiahe & Shale & Sichuan Basin & Marine & Triassic epoch \\
\hline GCG & Ganchaigou & Shale & Qaidam Basin & Continental & Paleogene \\
\hline $\mathrm{SHZ}$ & Shihezi & Sandstone & Erdos Basin & Continental & Early Permian \\
\hline
\end{tabular}

Table 2

XRD mineralogy analysis.

\begin{tabular}{|c|c|c|c|c|c|c|c|c|c|c|}
\hline \multirow[t]{2}{*}{ Label } & \multicolumn{5}{|c|}{ Mineral composition, wt.\% } & \multicolumn{5}{|c|}{ Relative abundance, wt.\% } \\
\hline & Quartz & Feldspar & Calcite & Dolomite & Clay & Smectite & Illite & $\mathrm{I} / \mathrm{S}^{\mathrm{a}}$ & Chlorite & Kaolinite \\
\hline LJP & 29.4 & 7.2 & 24.7 & 14.9 & 23.7 & 7.6 & 23.6 & 53.2 & 8.0 & 7.6 \\
\hline LMX & 40.3 & 8.8 & 7.5 & 6.5 & 36.9 & 4.3 & 15.9 & 62.3 & 8.7 & 8.7 \\
\hline NTT & 31.2 & 15.8 & 11.5 & 18.2 & 23.3 & 3.4 & 5.2 & 78.9 & 12.4 & 0 \\
\hline $\mathrm{XJH}$ & 45.2 & 10.5 & 6.2 & 0 & 38.3 & 7.5 & 10.8 & 80.2 & 0 & 1.5 \\
\hline GCG & 30.5 & 6.1 & 4.3 & 4.8 & 55.0 & 0 & 12 & 38 & 4 & 46 \\
\hline $\mathrm{SHZ}$ & 32.2 & 26.4 & 5.1 & 25.8 & 10.3 & 0 & 100.0 & 0 & 0 & 0 \\
\hline
\end{tabular}

${ }^{a}$ Note: $\mathrm{I} / \mathrm{S}$ is the Illite/smectite mixed-layer.

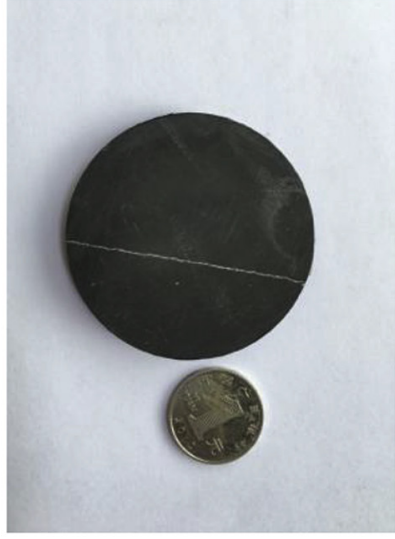

(a)

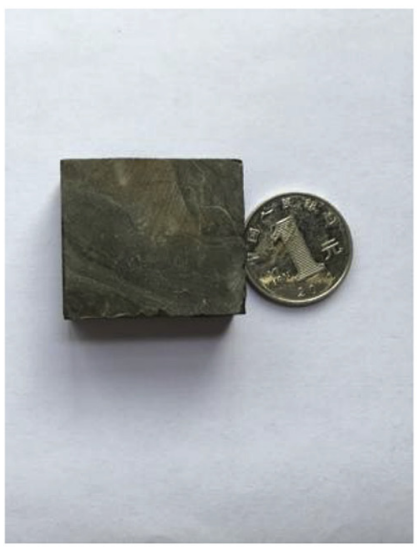

(d)

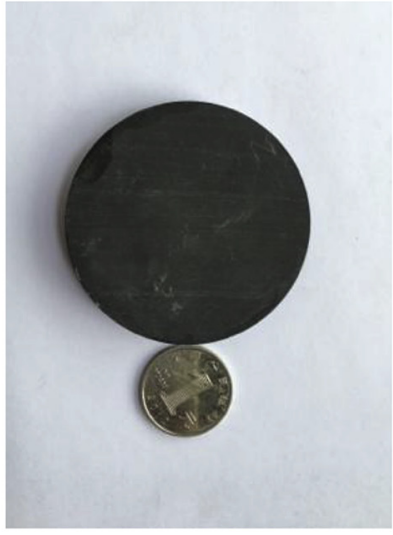

(b)

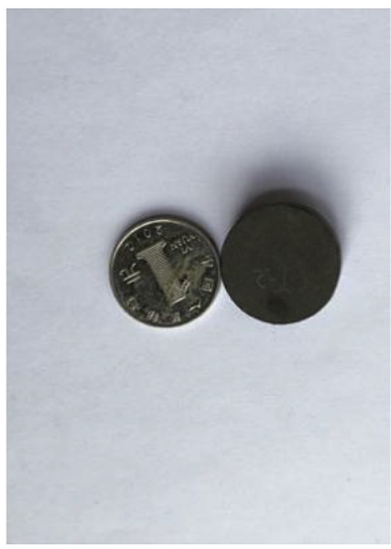

(e)

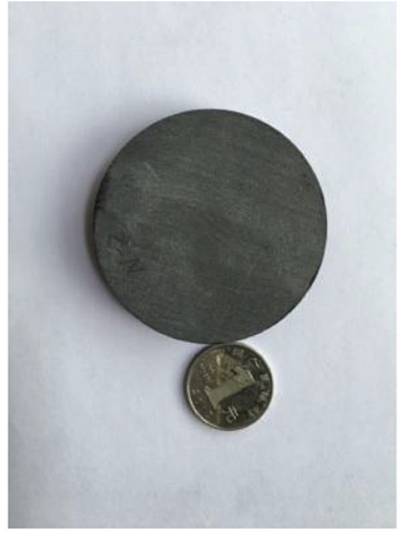

(c)

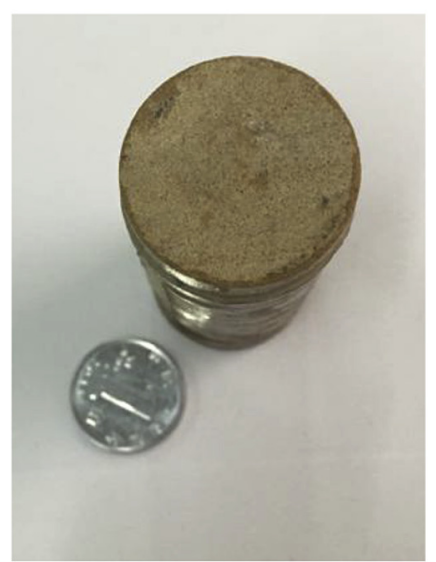

(f)

Fig. 1. The pictures of samples: (a) LJP-1, (b)LMX-1, (c)NTT-1, (d) XJH-1, (e)GCG, (f)SHZ. 
Table 3

Basic properties of core plugs for imbibition experiments.

\begin{tabular}{|c|c|c|c|c|c|}
\hline No. & Shape & Cross-sectional area $A_{c}, \mathrm{~cm}^{2}$ & Length $L, \mathrm{~cm}$ & Boundary condition & Ion diffusion rate, $(\mathrm{uS} / \mathrm{cm}) /\left(\mathrm{cm}^{2} \cdot \mathrm{h}^{0.5}\right)$ \\
\hline LJP-1 & Cylinder & 29.1 & 0.945 & TEO & 0.1309 \\
\hline LJP-2 & Cylinder & 29.3 & 1.036 & TEO & 0.1527 \\
\hline LMX-1 & Cylinder & 30.2 & 1.056 & TEO & 0.3013 \\
\hline LMX-2 & Cylinder & 30.1 & 1.075 & TEO & 0.2937 \\
\hline NTT-1 & Cylinder & 29.6 & 1.083 & TEO & 0.1321 \\
\hline NTT-2 & Cylinder & 29.7 & 1.041 & TEO & 0.1424 \\
\hline $\mathrm{XJH}-1$ & Rectangular & 11.8 & 1.451 & TEO & 0.3312 \\
\hline $\mathrm{XJH}-2$ & Rectangular & 11.9 & 1.436 & TEO & 0.3431 \\
\hline GCG-1 & Cylinder & 5.3 & 0.887 & TEO & 0.1363 \\
\hline GCG-2 & Cylinder & 5.3 & 0.885 & TEO & 0.1095 \\
\hline SHZ-1 & Cylinder & 4.9 & 5.101 & OEO & 0.0303 \\
\hline SHZ-2 & Cylinder & 4.9 & 3.214 & OEO & 0.0201 \\
\hline
\end{tabular}

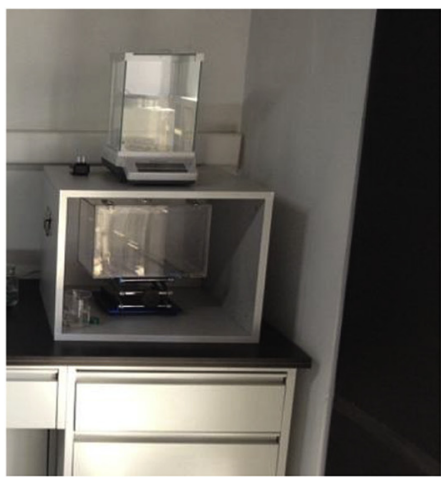

(a)

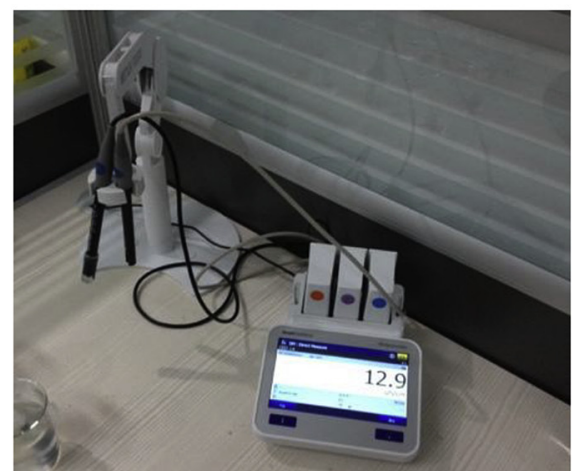

(b)

Fig. 2. The equipment used for imbibition and ion diffusion experiments: (a) the analytical balance, (b) the conductivity meter.

comprises the following steps:

(1) Dry the sample at $105{ }^{\circ} \mathrm{C}$ until the weight remains unchanged.

(2) Mix the epoxy and hardeners with the mass ratio of 3:1, and use a cotton ball to daub the mixture on the faces of samples according to the boundary conditions (Table 3). Then, naturally dry the samples for half an hour to reach the strength requirements.

(3) Put the sample in a $2500 \mathrm{ml}$ beaker with $200 \mathrm{ml}$ water. Freshkeeping film is used to seal the beaker to reduce electric conductivity deviation due to water evaporation.

(4) After a period of time, remove the sample gently with forceps, use the absorbent paper to take up the surface water, and measure the sample mass and water electricity conductivity, as shown in Fig. 3.

(5) Repeating steps (3) and (4) to record the sample mass and water electric conductivity at different times.

It is worth noting that removing the sample from the water bath may be associated with any uncertainty in the experimental results. Nevertheless, the experimental measurements could be convincing measurements as many researchers have asserted (Dehghanpour et al., 2013; Meng et al., 2015; Ghanbari and Dehghanpour, 2015).

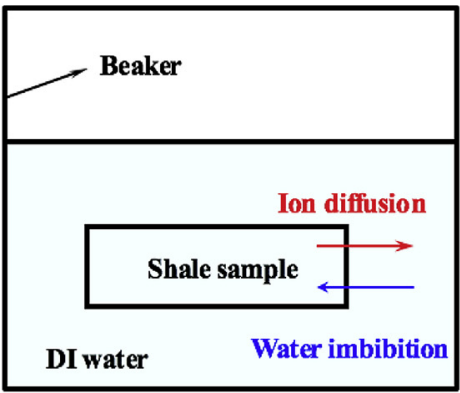

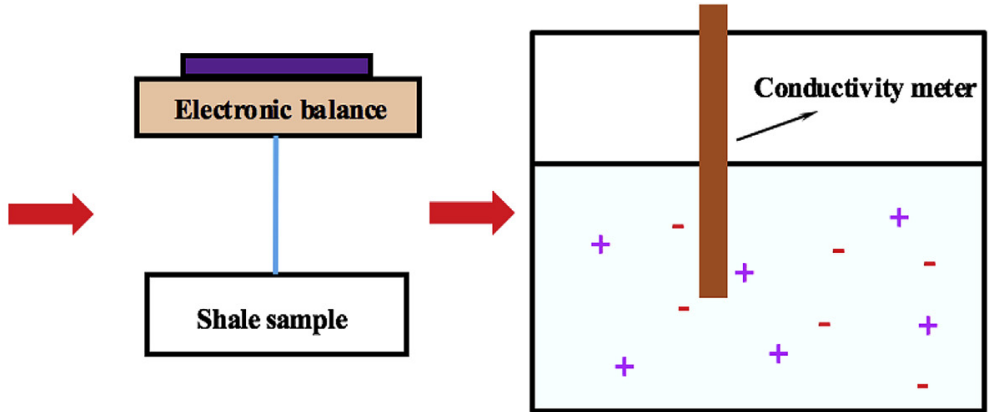

Fig. 3. The schematic of test procedure. 


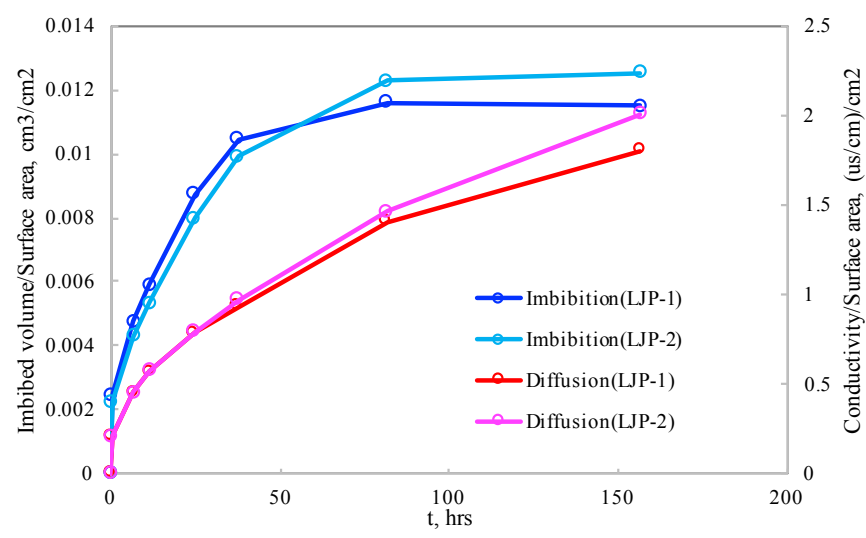

(a)

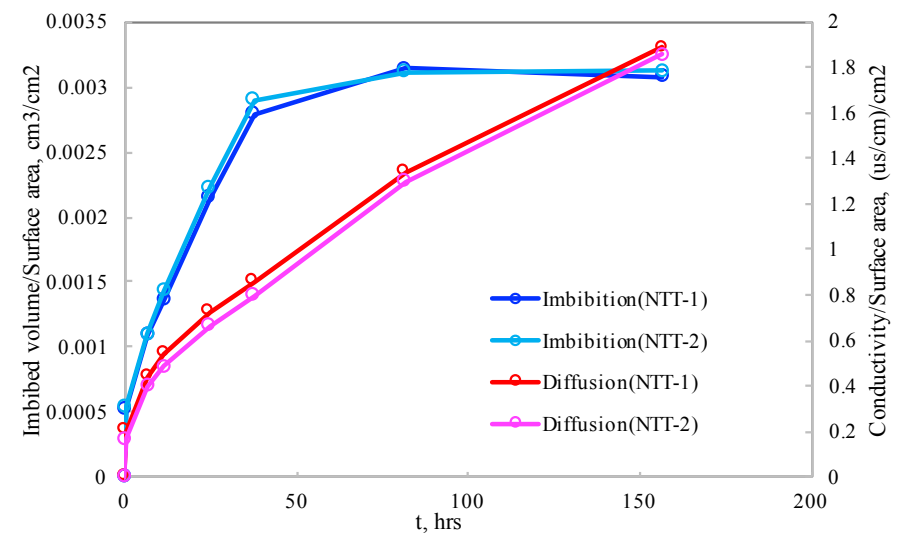

(c)

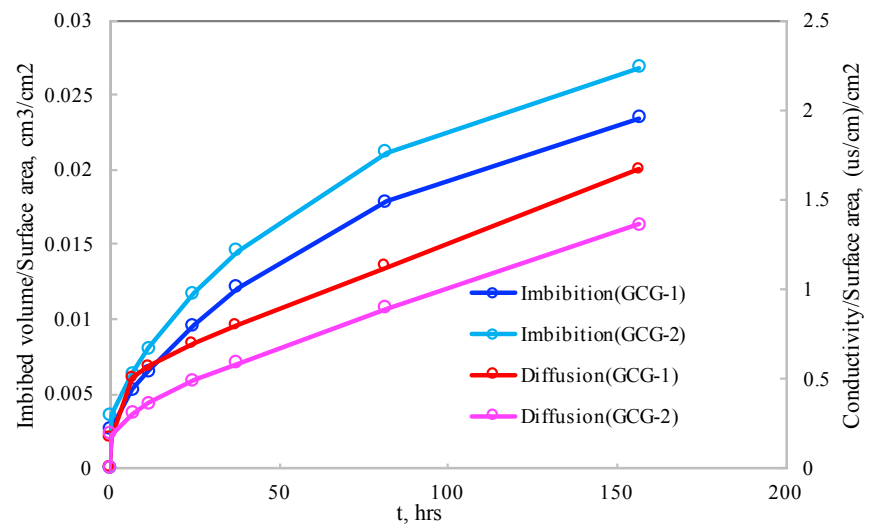

(e)

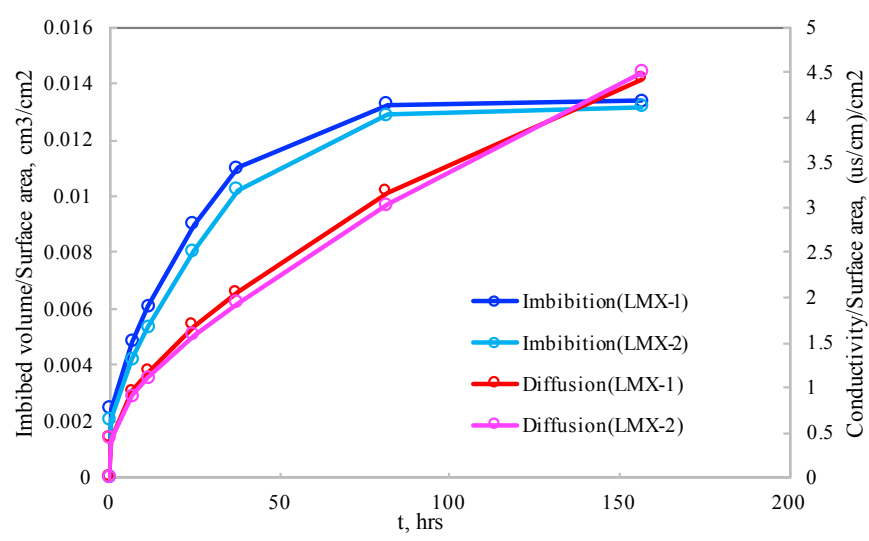

(b)

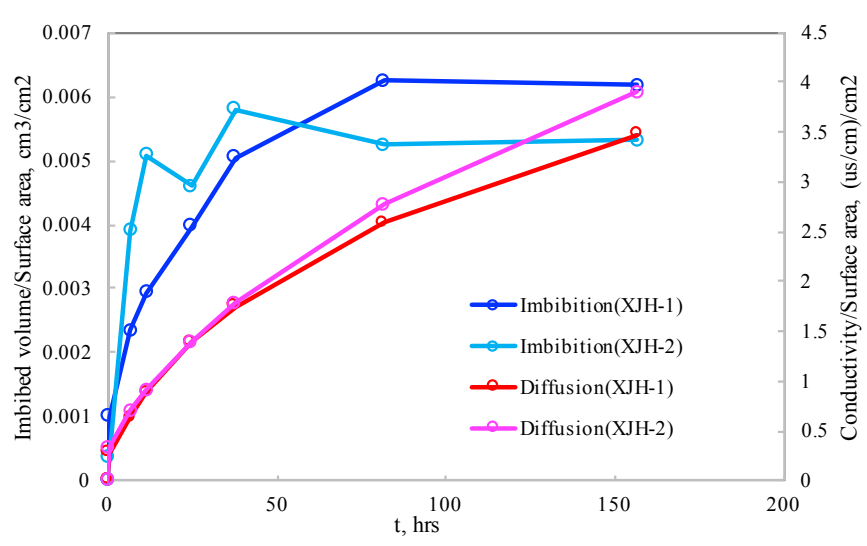

(d)

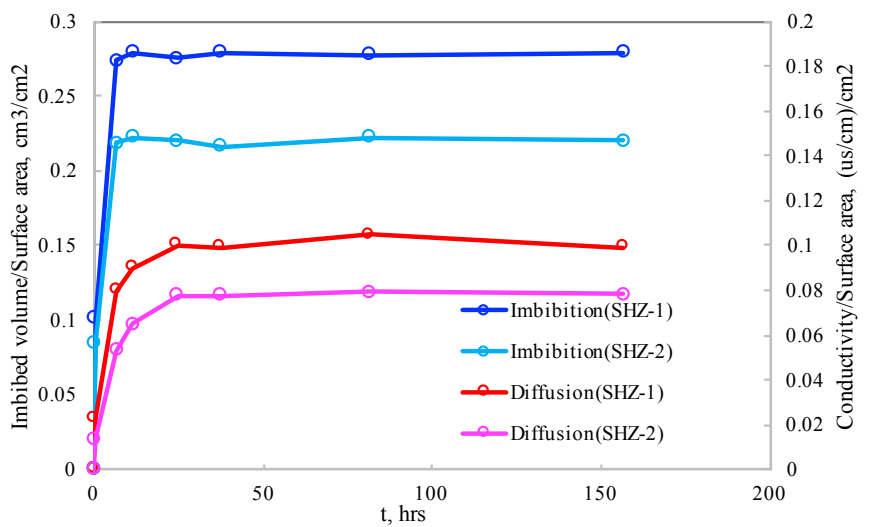

(f)

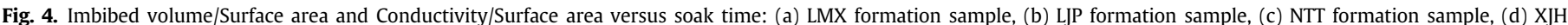
formation sample, (e) GCG formation sample, (f) SHZ formation sample.

\section{Experimental results}

\subsection{The behaviors of imbibition/diffusion curves}

The imbibition/diffusion experiment plots are shown in Fig. 4. The imbibed water volume and water conductivity gradually increase with soaking time, but the slope of the curves obviously decreases slowly and tends to be zero in the "plateau" stage.
Comparatively speaking, the imbibition curve is much quicker to present a "plateau" than the conductivity curve. In addition, the electricity conductivity and imbibition curves of sandstone achieve the "plateau" stage much more easily to than shale.

For liquid imbibition into gas-saturated rocks, Handy's (1960) imbibition model has been proposed for a horizontal piston-like imbibition process. The imbibed volume $V_{i m b}$ is given by 
$V_{i m b}=\sqrt{\frac{2 A_{c} \varnothing k_{w} S_{w f} P_{c}}{\mu_{w}}} \sqrt{t}$

where $P_{c}$ is the capillary pressure, $\mu_{w}$ is the viscosity of water, $k_{w}$ is the permeability of water, $\varnothing$ is the porosity of rocks, $t$ is the imbibition time, $A_{c}$ is the surface area and $S_{w f}$ is the front water saturation.

The imbibed volume/surface area is mathematically given by:

$V_{i m b} / A_{c}=\sqrt{\frac{2 \emptyset k_{w} S_{w f} P_{c}}{\mu_{w}}} \sqrt{t}=A \sqrt{t}$

where $A$ is the imbibition rate.

It is found that a positive proportional relationship exists between the imbibed volume/surface area and the square root of time. The plots of cumulative imbibed volume/surface area versus the square root of time are used to present the imbibition characteristics. A general observation indicates that each imbibition curve tends to be divided into three parts: a linear imbibition part (region 1), a transition part (region 2), and a plateau part (region 3), as shown in Fig. 6. The three regions are quite different from each other, which can be attributed to capillary pressure as a function of water saturation. As the water is imbibed into shale, the water saturation increases, resulting in the decline of capillary pressure. Therefore, the imbibition rate decreases, and a transition from the high imbibition rate of region 1 to the much slower imbibition rate of regions 2 and 3 is observed in most of the imbibition experiment curves.

Fig. 5 also demonstrates the plots of water conductivity/surface area versus the square root of time. Interestingly, there is a proportional relationship between conductivity gains and the square root of time. Moreover, the behavior of conductivity curves is similar to that of imbibition curves. It indicates that the imbibition correlates well with ion diffusion, and the law of ion diffusion is also similar to that of imbibition. Considering the same water volume in the beakers, the conductivity/surface area may be mathematically given by

$G / A_{c}=D \sqrt{t}$

where $\mathrm{G}$ is water conductivity and $\mathrm{D}$ is the ion diffusion rate.

Conventional sandstone could act as a calibration standard due to its known characteristics (e.g., high permeability, low clay content and simple pore structure) and help us understand the physical process in reservoir rocks. In contrast to shale samples, it is much easier for the sandstone samples to reach the equilibrium state of the physical process such as imbibition and ion diffusion. Except for the sandstone samples, the conductivity curves of shale samples present only one linear part, as shown in Fig. 5(a)-5(e). According to the characteristics of sandstone electric conductivity curves, it is speculated that the shale electric conductivity curve probably has the "three-stage" feature (Fig. 6). It may, however, require a much longer test time to achieve the equilibrium state (Region 3). The three regions of the conductivity curve can be addressed by the difference in salt concentration between shale and water. The ion diffusion into water conforms to Fick's first law of diffusion (Treybal, 1980). The transport rate $J$ is given by:

$J=-D_{A B}\left(\frac{\partial C_{A B}}{\partial x}\right)$

where $D_{A B}$ is the diffusion coefficient, $C_{A B}$ is the concentraton difference between shale and fluid and $\mathrm{x}$ is the distance from the shale interface.

According to Fick's first law, ion diffusion is induced by differences in salt concentration. The larger concentration difference can result in a higher ion transport rate. With the salt ions of the sample diffusing into fluid under the concentration difference, the salt concentration of water increases, resulting in a decreasing concentration difference. Moreover, this is more obvious in the solution of fixed volume. In the final region (region 3 ), the concentration difference tends to be zero, and the ion diffusion finally stops.

It should be mentioned that the behaviors of imbibition curves vary significantly in different formation samples despite the similar overall characteristics. Furthermore, the relationship between the imbibed volume/surface area and $\sqrt{t}$ is not a rigid straight line (Fig. 5). It can be addressed by different pore structures, including pore shape, topology (e.g., pore connectivity) and size distribution (Yang et al., 2016). In addition, the conductivity gain of $\mathrm{XJH}-2$ has some vibrations as a function of $\sqrt{t}$, as presented by Fig. 5(d). It may be attributed to the strong heterogeneity such as microfractures and pore tortuosity. The larger pores or fractures are connected to pore systems dependent on smaller pores, which results in the obvious vibrations of the imbibition rate.

All the imbibition/diffusion curves have a much larger slope at the initial stage, as shown in Figs. 5 and 6. This phenomenon, which is of great importance, has been neglected in previous studies. The intercept of the imbibition/diffusion curves tends to indicate the characteristics of the rock surface. As for the imbibition curves, $V_{\mathrm{i}} / A_{\mathrm{c}}$ is caused by the surface retention of water, but not by water imbibition. Owing to the roughness of the rock surface, the water can immediately embed into the grooves and can scarcely move when it comes into contact with the surface (Fig. 7). The embedded water cannot be wiped away during the experiments. Similarly, for the diffusion curves, $G_{\mathrm{i}} / A_{\mathrm{c}}$ is caused by the surface advection of salt ions, but not by ion diffusion. The modes of ion transportation include advection and diffusion (Ghanbari et al., 2013). Once the rock is put into the water, the water "slips" the rock, and the salt ion enters into water with the action of advection (Fig. 7). Unlike imbibition and salt diffusion, the water retention and salt ion advection occur quite quickly. During the fracturing operations, when the slick water "slips" the rough fracture network with a large surface area, the effects of water retention and ion advection are quite obvious and cannot be neglected, which are the main mechanisms for low flowback efficiency and high-salinity flowback water. It should be mentioned that the samples used in experiment are machined by cutting and drilling. Hence, the value of $V_{\mathrm{i}} / A_{\mathrm{c}}$ and $G_{\mathrm{i}} / A_{\mathrm{c}}$ in this experiment cannot reflect the surface properties of induced fractures. In future work, related experiments could be conducted to study water retention and salt ion advection due to the surface effects of the fracture network.

\subsection{The effects of clay minerals on imbibition/diffusion rate}

From the mineral analysis results in Table 2, shale is composed of quartz and clay. Because quartz has low sensitivity to water, the imbibition/diffusion properties depend largely on the clay mineral content and type. In our previous experiments (Ge et al., 2015), we found that the imbibition rate is positively related to the concentration of total clay mineral and $\mathrm{I} / \mathrm{S}+$ smectite. No relationship is found between illite concentration and imbibition rate. In this manuscript, the average diffusion rates of different formations are calculated and used to clarify the effects of clay minerals on the ion diffusion (Table 3). Fig. 8 presents the plots of average diffusion rate versus total clay, I/S + smectite and illite concentrations. Similar results are observed. The ion diffusion rate of all the samples indicates a positive correlation with the concentration of total clay 


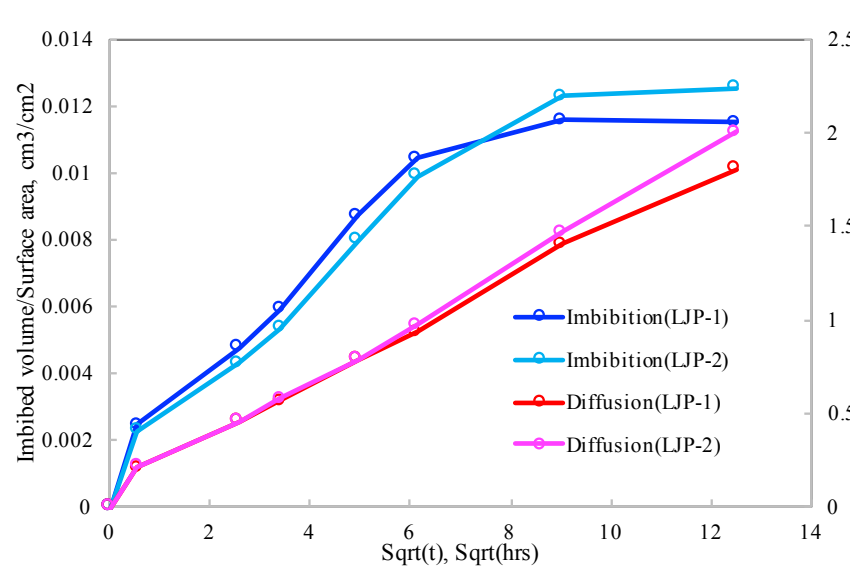

(a)

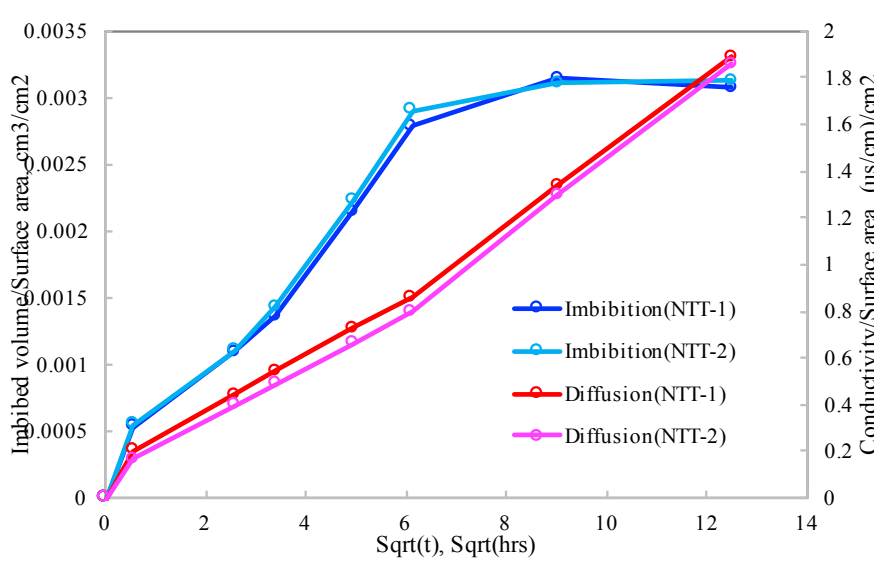

(c)

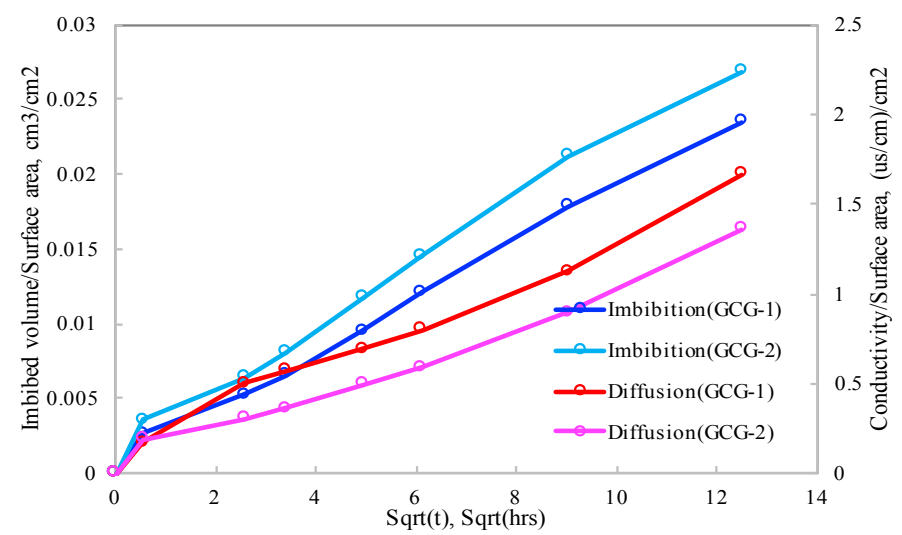

(e)

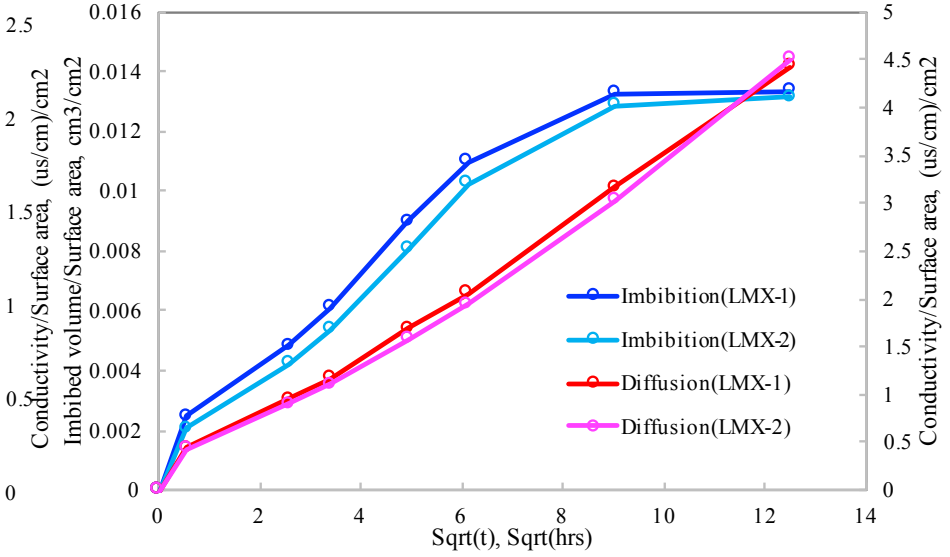

(b)

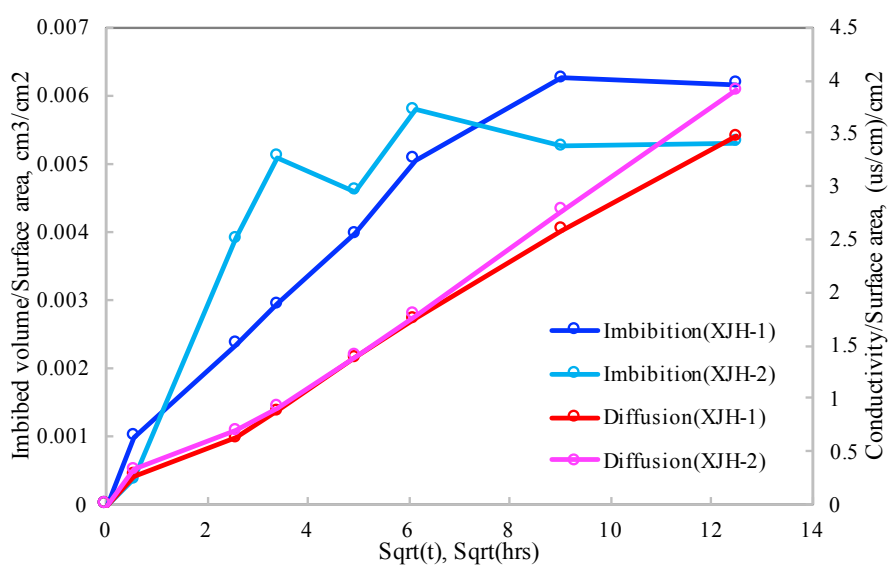

(d)

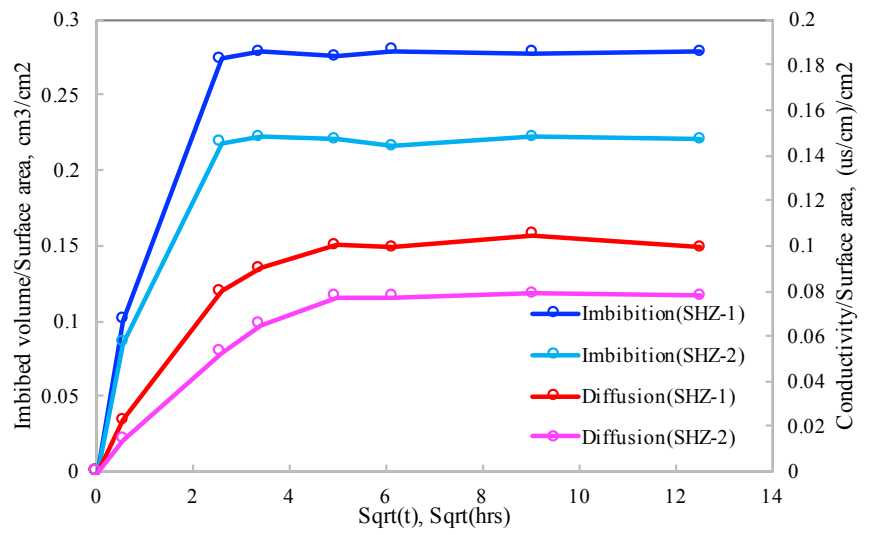

(f)

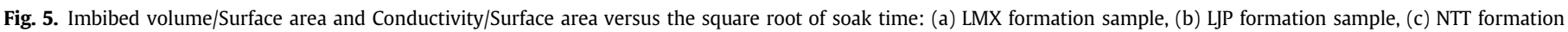
sample, (d) XJH formation sample, (e) GCG formation sample, (f) SHZ formation sample.

mineral and $\mathrm{I} / \mathrm{S}+$ smectite. The correlation coefficients are 0.22 and 0.81 , respectively, demonstrating that smectite and $\mathrm{I} / \mathrm{S}$ could enhance the ion diffusion rate. No relationship is observed between illite concentration and the ion diffusion rate, indicating that illite minerals do not significantly contribute to the ion diffusion rate in these clay-rich shales.
The clay mineral crystal layers are composed of silicon oxygen tetrahedron and aluminum-oxygen octahedron. The high valent cation in the surface and interior of the crystal layer (such as $\mathrm{Al}^{3+}$ ) can be partially replaced by low valence metal cations, resulting in a negatively charged clay surface. To maintain electric neutrality, the clay mineral surface attaches large amounts of exchangeable 


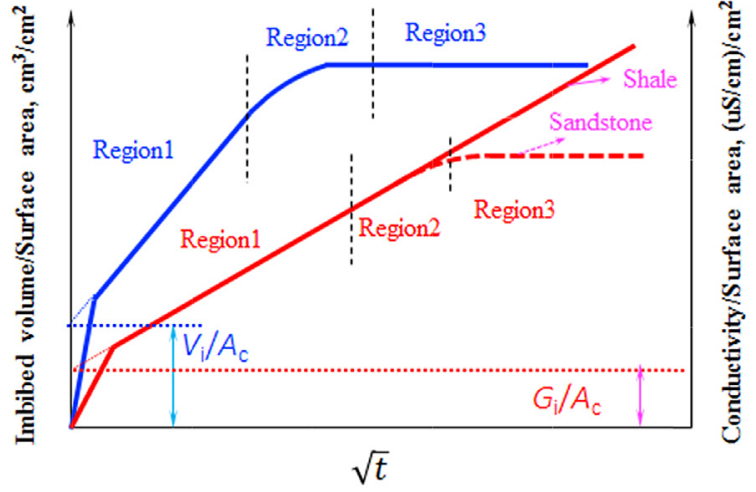

Fig. 6. The schematic of imbibition/diffusion curve behaviors. The red and blue curves stand for ion diffusion and imbibition curves respectively. (For interpretation of the references to colour in this figure legend, the reader is referred to the web version of this article.)

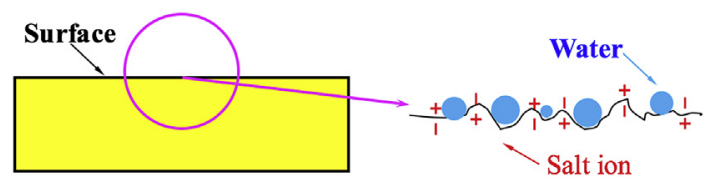

Fig. 7. The schematic of surface effects.
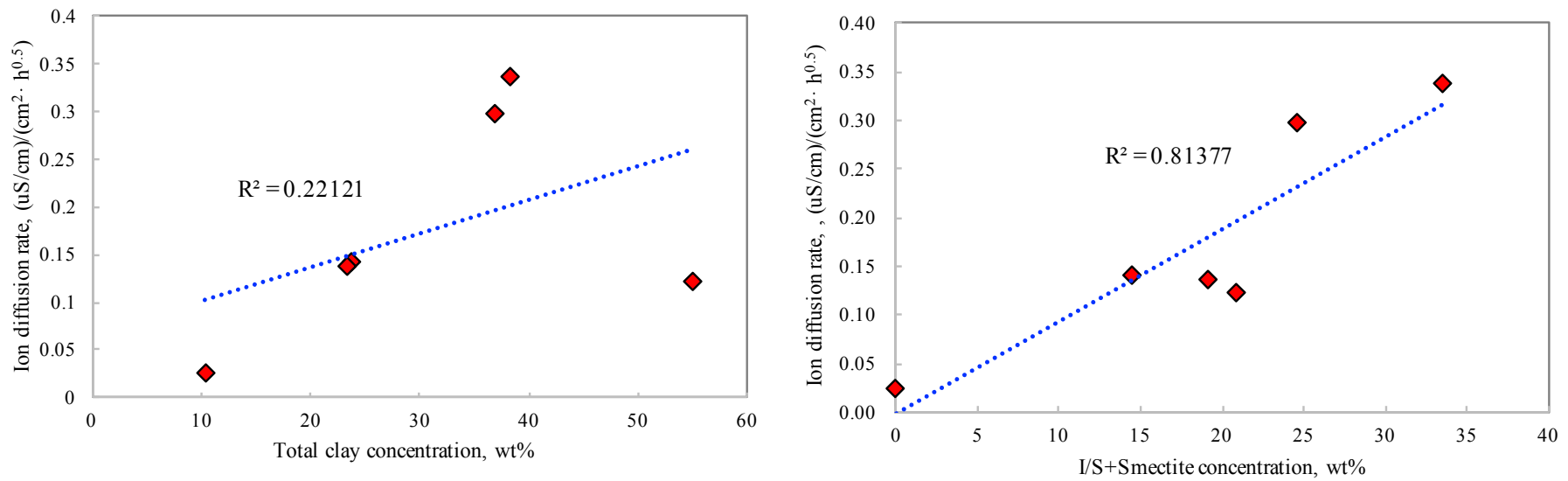

(a) cations. When clay minerals come into contact with low salinity water, the exchangeable cations absorbed on the clay surface are separated and enter into solution (Fig. 9). The remaining electronegative structural unit has a strong repulsive force to separate the crystal layer. Then, the water enters into the crystal layer to release ions continuously. Because the shale has the characteristics of a non-perfect semipermeable membrane, partial ions can pass through the shale crystal layer and diffuse into water, consequently enhancing the salinity of water (Facharoenphol et al., 2014).

In addition, the existence of clay also can increase the pore water salinity in gas shale. Shale formation has the characteristics of ultralow water saturation, which is relative to hydrocarbon generation drainage during deposition. As the ultra-low water saturation in organic-rich shale is generated under high pressure and extremely arid conditions, the formation water in steam form is expelled with the high temperature methane (Bennion and Thomas, 2005). Meanwhile, the clay crystal layer in the shale formation shows a preferable semipermeable property; thus a large fraction of crystalline salt and high salinity water film is attached to the shale pore wall and clay mineral crystal layer (Kurtoglu, 2013), as shown in Fig. 9. Hence, it is clear that the amount of salt ions in shale formation is closely related to the depositional environment's water salinity and clay mineral content in gas shale. (b)

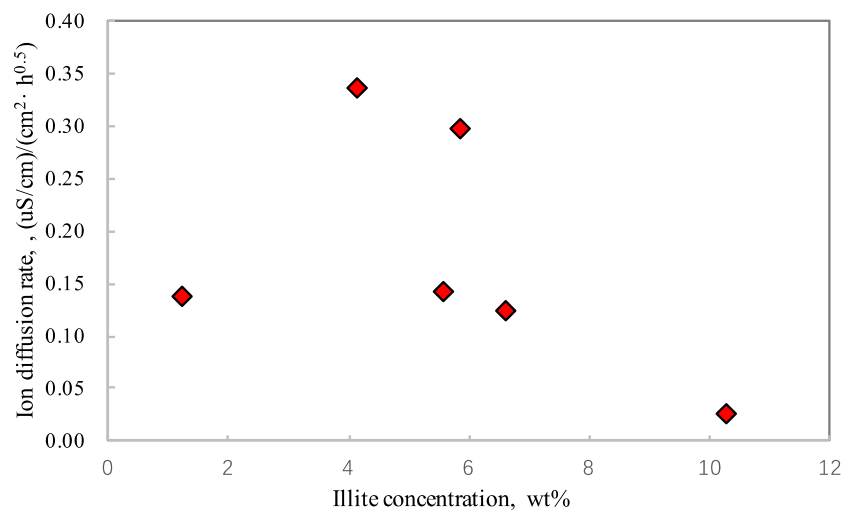

(c)

Fig. 8. Ion diffusion rate versus total clay, I/S + smectite and illite concentration: (a) Total clay concentration, (b) I/S + smectite concentration, (c) illite concentration. 

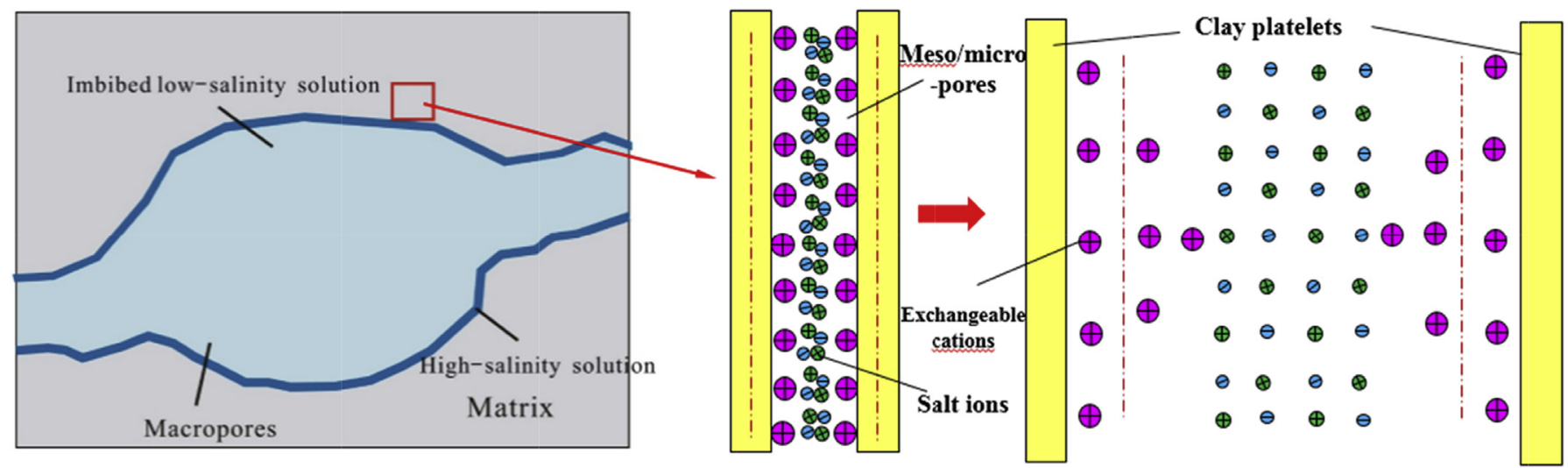

Fig. 9. The ion source of shale reservoir.

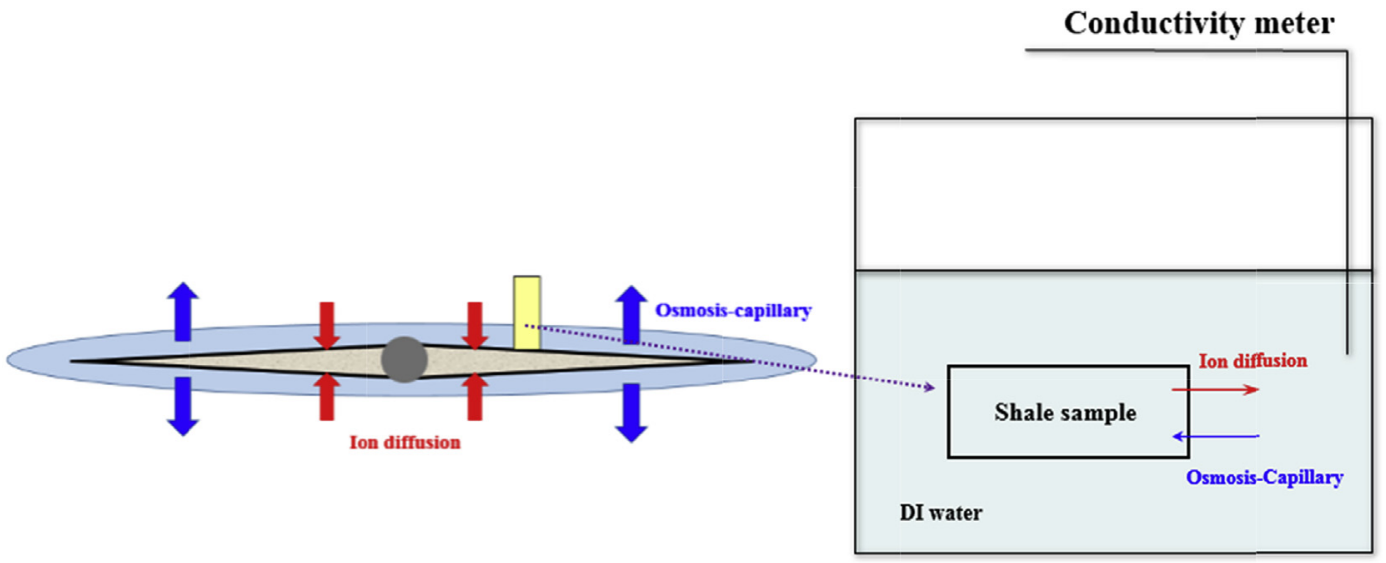

Fig. 10. Sketch of imbibition-diffusion mechanism.

\section{Quantitative interpretation of the imbibition/diffusion relationship}

As shown in Fig. 10, the ion diffusion process in the fracturing fluid is accompanied by the imbibition process that is jointly driven by capillary pressure and clay osmotic pressure (Ge et al., 2015). When the water hits the shale, the salt ions in the shale pore begin to dissolve or dilute and then diffuse into water. Fick's law suggests that the diffusions rate of salt ions is related to differences in concentration (Treybal, 1980). Compared with the salinity in shale formation, the salinity in injected slick water is generally low, which can be ignored. Thus the diffusion rate is relatively high and the diffusion process is very quick (Zolfaghari et al., 2015).

It is observed that imbibition-diffusion is a complicated physicchemical process. Moreover, the shale develops micro-fractures or macropores, mesopores and micropores, and the pore structure is highly complicated. Therefore, the mathematical model for imbibition/diffusion should be simplified to solve the equation easily. The initial stage of imbibition mainly involves the imbibition of micro-fractures or macro-pores, and then it slowly becomes mesopore or micropore imbibition at a later stage (Yang et al., 2016; Meng et al., 2015; Roychaudhuri et al., 2013). There is an obvious proportional relationship between the imbibition volume and square root of time in the initial stage, indicating that the microfractures and macro-pores imbibition model can be established based on the assumption of parallel straight capillary bundles. In the initial stage, the salt ions mainly come from the dissolution of

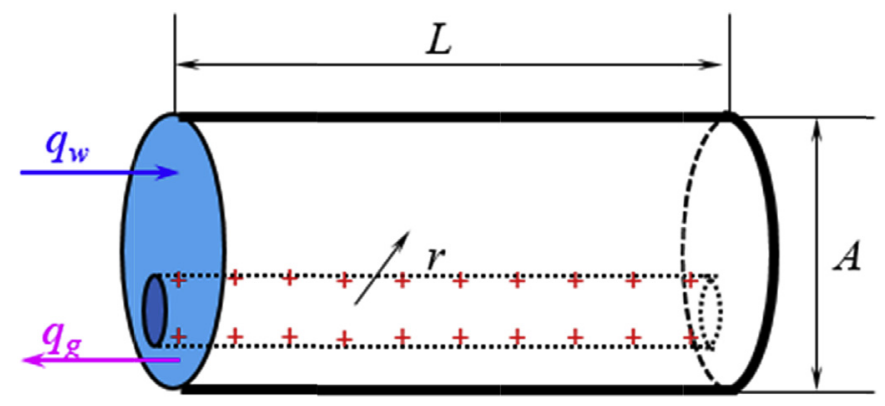

Fig. 11. The schematic of countercurrent imbibition.

crystalline salt in the surface of the macropores or the dilution of high salinity water film (Fig. 9). Therefore, depending on porous flow theory of gas-water two-phase, the mathematical model is established to analyze the correlativity relationship between imbibition and diffusion based on the assumption of parallel straight capillary bundles.

\subsection{Mathematic model}

To explore the correlation between imbibition and diffusion, the author establishes the countercurrent imbibition model (Fig. 11). Only one face can contact the water. To simplify the solution procedure, the authors make the following assumptions: 
(1) The imbibition process involves piston-like displacement of the gas-water phase. Compared with the capillary pressure and osmotic pressure, the gravity is too small and could be neglected during the description of water imbibition in gas shale.

(2) Shale is the ideal porous media, and the pore space is composed of the parallel straight capillary bundles.

(3) The salt ions are evenly attached to the pore wall.

(4) Once the salt ions contact the imbibition front, they will immediately dissolve and diffuse into the water to increase the conductivity of water.

According to the Darcy formula, the gas and water flow rate during imbibition are:

$$
\begin{aligned}
& \mathrm{q}_{g}(x)=\frac{k k_{r g}}{\mu_{g}} A_{c} \frac{d P_{g}}{d x} \\
& \mathrm{q}_{w}(x)=\frac{k k_{r w}}{\mu_{w}} A_{c} \frac{d P_{w}}{d x}
\end{aligned}
$$

where $\mathrm{q}_{g}(x)$ and $\mathrm{q}_{w}(x)$ are the gas and water flux, respectively; $k$ is absolute permeability; $k_{r g}$ and $k_{r w}$ are the relative permeability of gas and water, respectively; $\mu_{g}$ and $\mu_{w}$ are the viscosity of gas and water, respectively; $P_{g}$ and $P_{w}$ are the pressure of gas and water, respectively; and $A_{c}$ is the sectional area.

Only one face can contact the water and the volume of water and gas are equal, which is given below:

$\frac{k_{r g}}{\mu_{g}} \frac{d P_{g}}{d x}=-\frac{k_{r w}}{\mu_{w}} \frac{d P_{w}}{d x}$

The gas phase pressure in air-water interface is

$P_{g}=P_{w}+\left(P_{\pi}+P_{c}\right)$

where $P_{\pi}$ is osmotic pressure.

According to Murat and John (1996), it is assumed that the driving force gradient is $\left(P_{\pi}+P_{c}\right) / x$. Substituting (6) and (7) into (5) yields:

$\mathrm{q}_{\mathrm{w}}=-k A_{c \frac{1}{\mu_{g}} \frac{1}{k_{\mathrm{rg}}}+\frac{\mu_{w}}{k_{r w}}} \frac{\left(P_{\pi}+P_{C}\right)}{x}$

As water is imbibed into shale, the increased water volume inside the shale is

$V_{i m b}=\int_{0}^{x} A_{c} \varnothing\left(S_{w f}-S_{w i}\right) d x$

where $S_{w f}$ and $S_{w i}$ are front water saturation and initial water saturation respectively.

Then water flow rate is

$q_{\mathrm{w}}=A_{c} \varnothing\left(S_{w f}-S_{w i}\right) \frac{d x}{d t}$

The simultaneous Eqs. (8) and (9) is

$\frac{k}{\chi \varnothing\left(S_{w f}-S_{w i}\right)} \frac{P_{\pi}+P_{c}}{\mu_{g}}+\frac{\mu_{w}}{k_{r w}}=\frac{d x}{d t}$

After compilation, the imbibition front position changes over time. $x=\left[\frac{2 k\left(P_{\pi}+P_{C}\right) t}{\left(\frac{\mu_{g}}{k_{r g}}+\frac{\mu_{w}}{k_{r w}}\right) \varnothing\left(S_{w f}-S_{w i}\right)}\right]^{1 / 2}$

When the imbibition front arrives at $\mathrm{x}$, the salt ions dissolve and the concentration of salt ions is $S_{a}$ :

$S_{a}=\frac{2 \pi \mathrm{r} \cdot \mathrm{x} \cdot \mathrm{C} \cdot \mathrm{n} A_{c}}{\mathrm{~V}}$

The volume of imbibed water is:

$V_{i m b}=A_{c} x \emptyset\left(S_{w f}-S_{w i}\right)$

where $r$ is the average pore radius of shale, $n$ is the number of capillary tubes in unit cross-sectional area, $C$ is the quality of salt ions attached to the shale wall in per unit area, $V$ is the volume of solution.

Considering the effects of sectional area, the concentration of salt ions changes with time during imbibition:

$S_{a}=\frac{A_{c} C}{V}+\frac{2 \pi \mathrm{rnC} A_{C}}{V} \cdot\left[\frac{2 k\left(P_{\pi}+P_{c}\right) t}{\left(\frac{\mu_{g}}{k_{\mathrm{rg}}}+\frac{\mu_{w}}{k_{r w}}\right) \varnothing\left(S_{w f}-S_{w i}\right)}\right]^{\frac{1}{2}}$

According to Eqs. (3) and (11), the analytical solution for diffusion rate is given by

$D=\frac{2 \pi r n C}{V} \cdot\left[\frac{2 k\left(P_{\pi}+P_{c}\right)}{\left(\frac{\mu_{g}}{k_{r g}}+\frac{\mu_{w}}{k_{r w}}\right) \emptyset\left(S_{w f}-S_{w i}\right)}\right]^{\frac{1}{2}}$

The imbibed water volume changes with time is given by

$V_{i m b}=A_{c}\left[\frac{2 k\left(P_{\pi}+P_{c}\right) \emptyset\left(S_{w f}-S_{w i}\right) t}{\left(\frac{\mu_{g}}{k_{r g}}+\frac{\mu_{w}}{k_{r w}}\right)}\right]^{1 / 2}$

According to Eq. (11), the salinity of the solution has good proportional relationship with $\mathrm{t}^{0.5}$, which is consistent with Eq. (12) for imbibition. The previous imbibition/diffusion experiments demonstrate that both the imbibed water volume and electrical conductivity gain depend on $t^{0.5}$, which verifies the accuracy of the mathematical model.

From the prospective of the physics process, the imbibition front of the fracturing fluid contacts the pore wall and the salt ions immediately dissolve and diffuse into water. Therefore, the concentration of salt ions can reflect the movement rate of imbibition front. In other words, the water imbibition into gas shale and the ion diffusion into water proceed simultaneously in opposite direction. The quantitative interpretation of imbibition/diffusion relationship has obtained identification at IC3G 2016 conference of Melbourne.

The physical parameters of shale can be computed based on the assumption of capillary bundles.

$\emptyset=\mathrm{n} \pi r^{2}$

$\mathrm{k}=\frac{\emptyset r^{2}}{8}$ 
$p_{c}=\frac{2 \sigma \cos \theta}{r}$

$P_{\pi}=-\eta \frac{R T}{V} \ln \frac{A_{s h}}{A_{\mathrm{f}}}$

where $\sigma$ is the surface tension, $\theta$ is the wetting angle, $\eta$ is the membrane efficiency, $\mathrm{R}$ is the gas constant $(8.314 \mathrm{~J} / \mathrm{K} \cdot \mathrm{mol}), \mathrm{T}$ is the absolute temperature, $\mathrm{V}$ is the partial molar volume of water $\left(18 \times 10^{-6} \mathrm{~m}^{3} / \mathrm{mol}\right)$, and $A_{\mathrm{f}}$ and $A_{s h}$ are the activity of solution and fluid in shale pores, respectively. In addition, it is assumed that the gas mobility is equal to water mobility (Murat and John, 1996). At room temperature, the viscosities are $1 \mathrm{cP}$ for water and $0.018 \mathrm{cP}$ for gas. It is given by:

$\sqrt{\left(\frac{\mu_{g}}{k_{r g}}+\frac{\mu_{w}}{k_{r w}}\right)^{-1}}=0.13 c P^{-0.5}$

\subsection{Simulation results}

It is assumed that the shale sample with a diameter of $2.5 \mathrm{~cm}$ and length of $5 \mathrm{~cm}$ is placed in a beaker with $600 \mathrm{ml}$ water to record the variation of electrical conductivity. The mathematic model is used to analyze the relationship between imbibition and diffusion. In addition, the influencing factors are considered, which include porosity, permeability, initial water saturation, surface tension, wetting angle, sectional area, and the quality of salt ions attached to the shale wall in the unit area. The basic parameters are shown in Table 4.

Figs. 12-17 present the curves of conductivity and imbibed volume versus soaking time under various conditions. The imbibed water volume and water conductivity gradually increase with time, but the slope of the curves decreases slowly. In addition, the intersection of the conductivity curve and y-axis is the initial value $\mathrm{G}_{0}\left(\mathrm{G}_{0}=\mathrm{A}^{*} \mathrm{C} / 1.2\right)$, which is mainly related to the exposed area of the sample. They are consistent with the experimental results in Fig. 4. Because the contact area of the sample is relatively small during the experiments, the initial electrical conductivity due to surface effects is not obvious. If the fracturing fluid comes into contact with the fracture networks during fracturing operations, the salinity of the fracturing fluid would rise rapidly. In the following sections, the effects of a single parameter (i.e., permeability, porosity, initial water saturation, surface tension, water contact angle, sectional area and ion adhesion amount in unit area) on imbibition and diffusion process are analyzed by keeping other parameters constant. It is worth noting that both permeability and porosity are dependent on the capillary tube radius. In other words, it is the change in the capillary tube radius that leads to changes in permeability or porosity. Nevertheless, presenting the effects of permeability and porosity rather than capillary tube radius are more intuitive to researchers.

\subsection{1. (1)Permeability}

The comparison analysis of imbibition and ion diffusion curves are conducted by changing the permeability of shale samples, as shown in Fig. 12. Interestingly, as the permeability increases, the ion diffusion rate decreases, while the imbibition rate increases. Although the permeability can increase the front movement rate, the increase of permeability actually decreases the specific area. The salt ions are mainly attached to interior surface, and the reduction of specific area directly reduces the ion diffusion rate. And this is probably a good explanation that why the ion diffusion rate of conventional reservoir is lower than that of shale reservoir (Table 3).

\subsection{2. (2)Porosity}

The comparison analysis of imbibition and ion diffusion curves are conducted by changing the porosity of the shale sample ( $1 \%, 2 \%$ and 3\%), as shown in Fig. 13. It is observed that as the porosity increases, both the diffusion and imbibition rate can significantly increase. It suggests that the porosity is one of the main controlling factors affecting the imbibition and ion diffusion.

\subsection{3. (3)Initial water saturation}

The alteration of the initial water saturation $(0.2,0.3$ and 0.4$)$ can also affect the imbibition and ion diffusion rate, as shown in Fig. 14. As the initial water saturation increases, the ion diffusion rate rises, but the imbibition rate decreases.

\subsection{4. (4)Surface tension}

Fluids with varying surface tensions $(0.053 \mathrm{~N} / \mathrm{m}, 0.063 \mathrm{~N} / \mathrm{m}$ and $0.073 \mathrm{~N} / \mathrm{m}$ ) are used to analyze the effects of surface tension on imbibition and diffusion, as shown in Fig. 15. It is seen that the imbibition and ion diffusion rate do not increase notably as the surface tension increases, which indicates that surface tension is not the main controlling factor for the imbibition and diffusion rate.

\subsection{5. (5)Water contact angle}

As Fig. 16 shows, the variation of the water contact angle $\left(10^{\circ}\right.$, $20^{\circ}$ and $30^{\circ}$ ) would affect the imbibition and ion diffusion rate. It is demonstrated that the ion diffusion and imbibition rate would decrease as the water contact angle increases.

\subsection{6. (6)Sectional area}

The effects of various sectional areas $\left(5 \mathrm{~cm}^{2}, 10 \mathrm{~cm}^{2}\right.$ and $\left.15 \mathrm{~cm}^{2}\right)$ on ion diffusion and water imbibition are shown in Fig. 17. As the sectional area increases, the ion diffusion and imbibition rate increase rapidly. Thus, the sectional area is one of the main controlling factors for imbibition and diffusion.

\subsection{7. (7)Ion adhesion amount in unit area}

The ion adhesion amount in the unit area $\left(0.004 \mathrm{mg} / \mathrm{cm}^{2}\right.$, $0.0056 \mathrm{mg} / \mathrm{cm}^{2}$ and $0.0072 \mathrm{mg} / \mathrm{cm}^{2}$ ) is altered to detect its influence on ion diffusion, as shown in Fig. 18. It is observed that the ion diffusion rate increases significantly with the increase of the ion adhesion amount in the unit area. The ion adhesion amount in the unit area is the main controlling factor. According to Eq. (12), the ion adhesion amount in the unit area would not affect the

Table 4

Basic parameters.

\begin{tabular}{|c|c|c|c|c|}
\hline Permeability/md & Porosity/\% & Initial water saturation & Surface tension/(N/m) & Wetting angle $/^{\circ}$ \\
\hline 0.0008 & 2.0 & 0.2 & 0.073 & 30 \\
\hline Sectional area $/ \mathrm{cm}^{2}$ & Shale activity & Membrane efficiency & Ion adhesion amount in unit area $/\left(\mathrm{mg} / \mathrm{cm}^{2}\right)$ & \\
\hline 4.9 & 0.9 & 0.2 & 0.0056 & \\
\hline
\end{tabular}




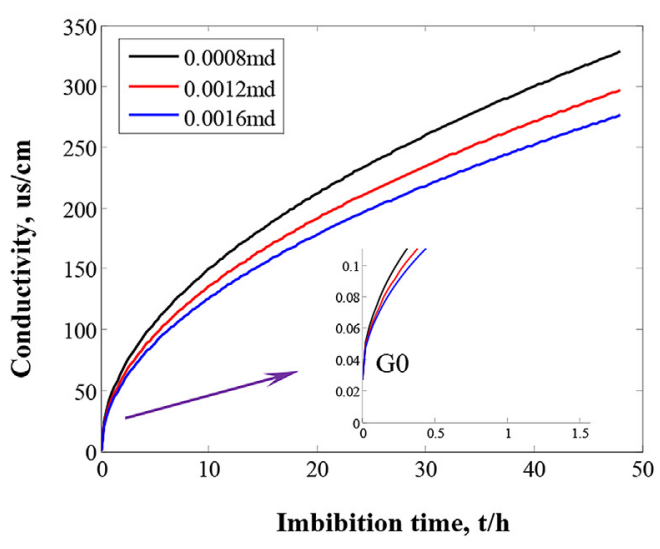

(a)

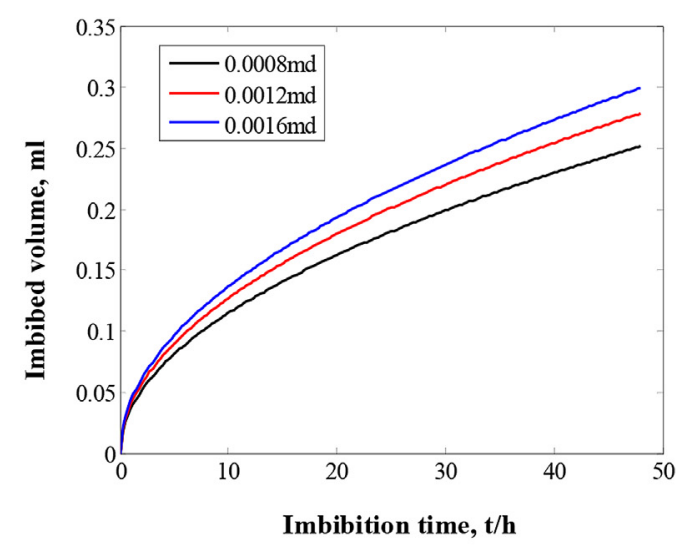

(b)

Fig. 12. The effects of permeability on imbibition/diffusion.

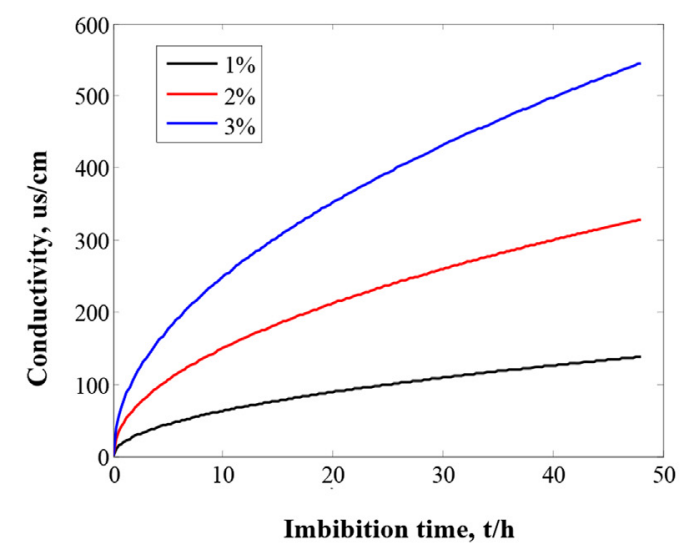

(a)

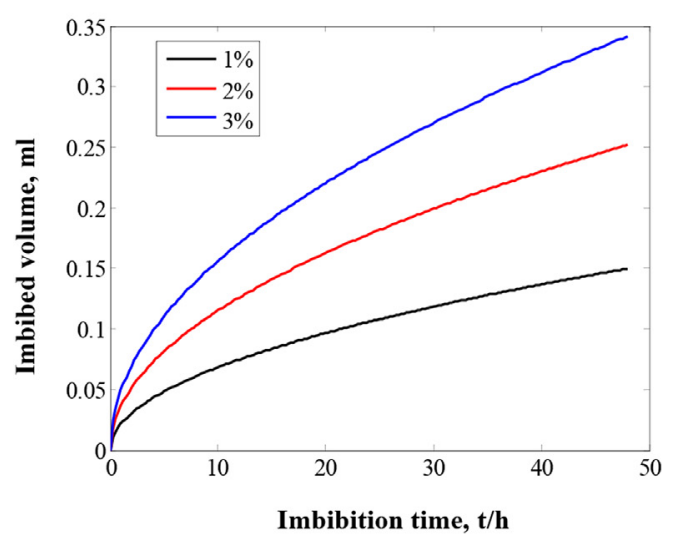

(b)

Fig. 13. The effects of porosity on imbibition/diffusion.

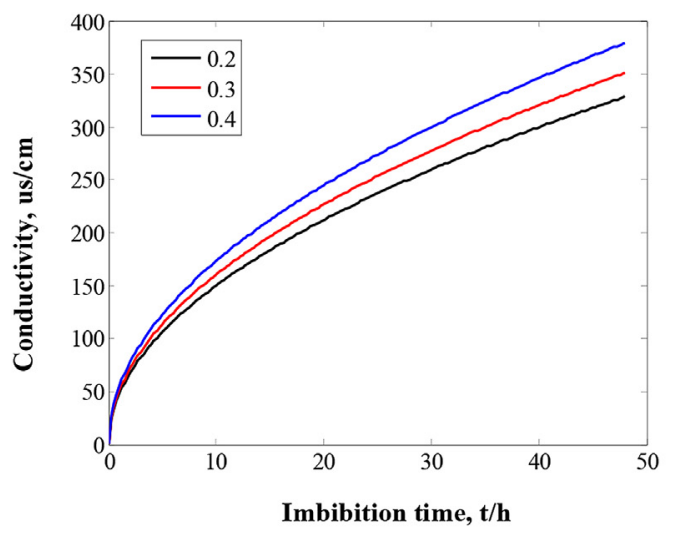

(a)

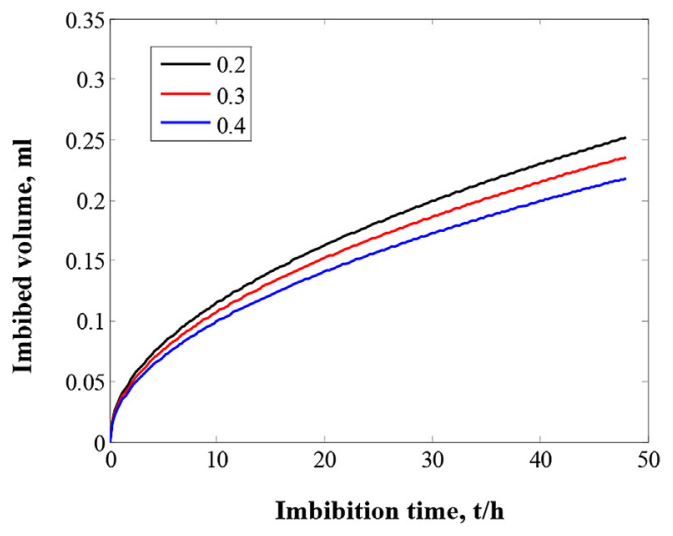

(b)

Fig. 14. The effects of initial water saturation on imbibition/diffusion.

imbibition rate.

Generally, the effects of porosity, surface tension, contact area and wetting angle on water imbibition rate are in consistent with the effect on the ion diffusion rate. The permeability, however, shows a positive correlation with the imbibition rate and a negative correlation with the ion diffusion rate. The initial water saturation 


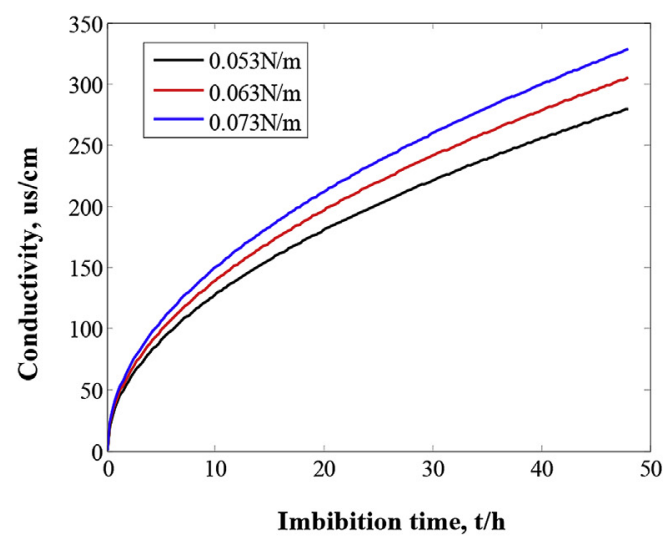

(a)

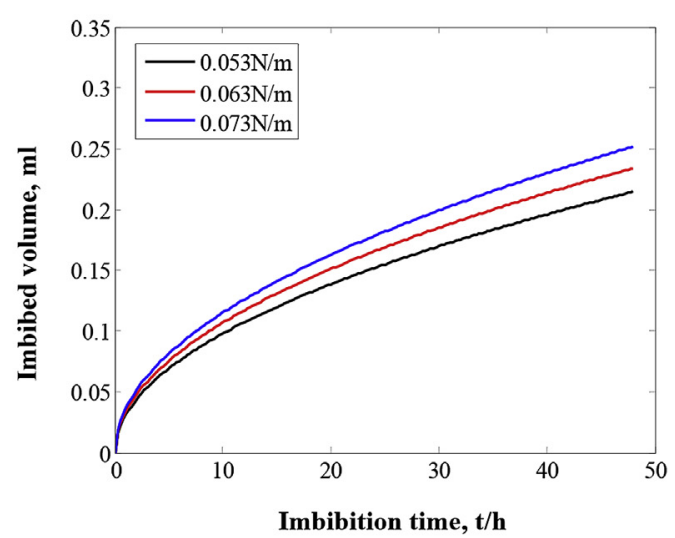

(b)

Fig. 15. The effects of surface tension on imbibition/diffusion.

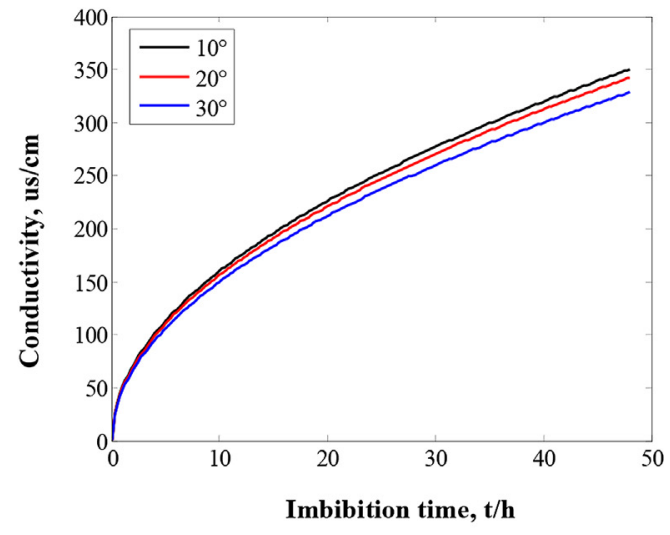

(a)

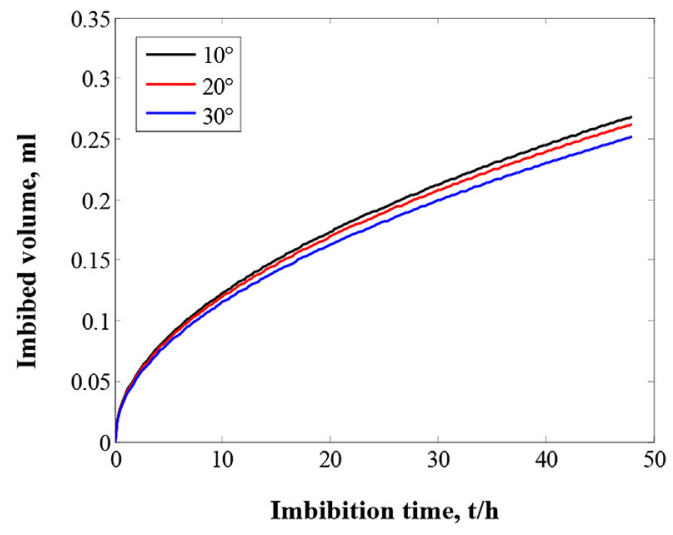

(b)

Fig. 16. The effects of contact angle on imbibition/diffusion.

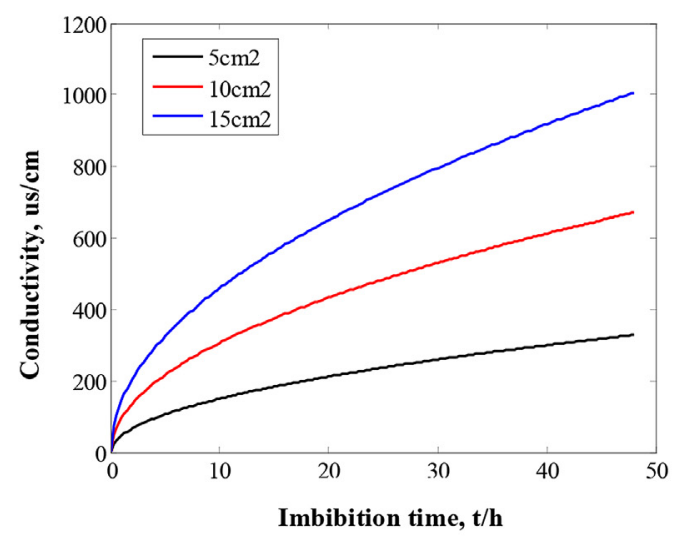

(a)

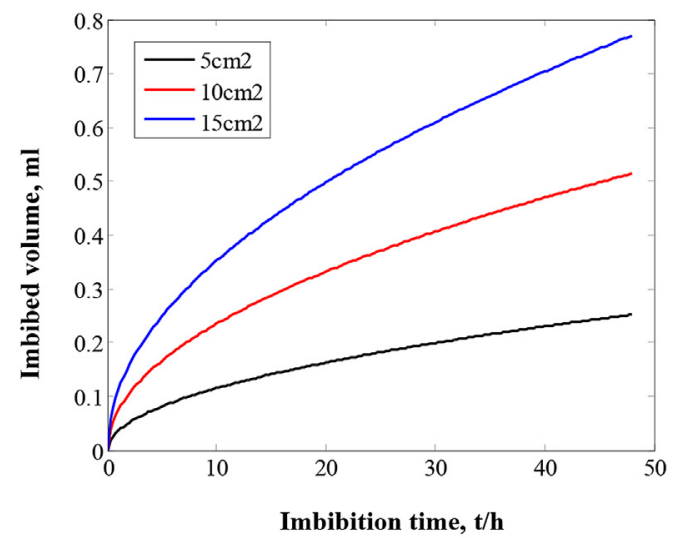

(b)

Fig. 17. The effects of sectional area on imbibition/diffusion.

is negatively related to the imbibition rate and positively related to the ion diffusion rate. It should be noted that the amount of ion adhesion in the unit area is positively related to the ion diffusion rate. There is no relationship between the ion adhesion amount in the unit area and imbibition rate. 


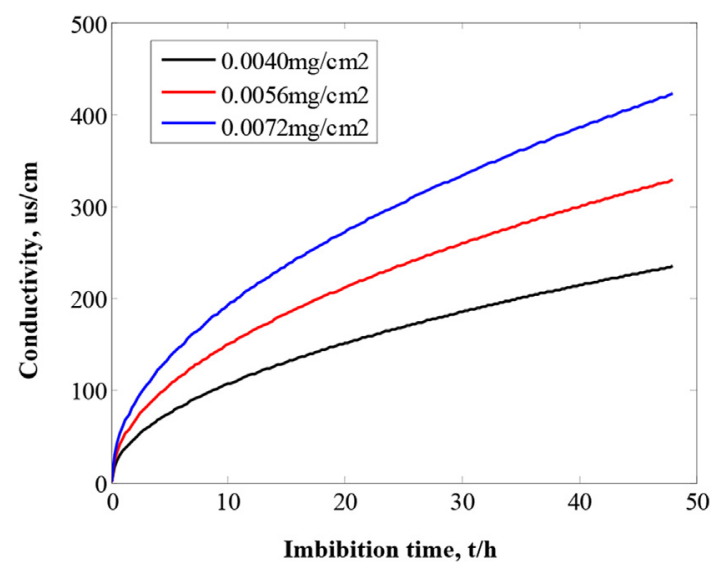

Fig. 18. The effects of ion content in unit surface area on imbibition-diffusion.

\section{Discussions}

The Handy imbibition model depending on piston-like horizontal displacement was developed for conventional rocks. In addition, the mathematical model of imbibition/diffusion was established based on the assumption of parallel straight capillary bundles, which is suitable for imbibition in conventional reservoir pores or shale reservoir macro-pores. Therefore, the validity of the imbibition-diffusion model for gas shale is doubtful in this manuscript. At present, there is no perfect model to describe the imbibition process of gas shale due to its complex pore structure and mineral composition. The Handy model can still be used to conduct semi-quantitative analysis for gas shale by many researchers (Lan and Dehghanpour, 2014). It should be noted that the overall trend predicted remains useful and believable. Furthermore, the innovative point in this manuscript is to clarify the relationship between imbibition and ion diffusion depending on experiments and simple theoretical derivation. The development of an imbibition model for gas shale is not the main emphasis. In future work, a tree branch model based on the fractal theory will be developed to depict the complex pore structure in gas shale and describe the imbibition/ diffusion process.

In Fig. 5, the imbibition curves can quickly exhibit the transition part and plateau part, whereas the diffusion curves still present the growth trend. According to the imbibition/diffusion model, imbibition and ion diffusion proceed simultaneously and synchronously. Therefore, water imbibition would probably still continue, which can be explained by shale's complicated pore structure. The pore structure in the shale reservoir is very different from that of a conventional reservoir. The pores in a conventional reservoir are mainly macropores, which can be described by the parallel straight capillary bundle model. Shale, however, develops micro-fractures or macropores, mesopores and micropores. The pore structure is more complicated and can be described by the fractal theory. For the imbibition of liquid into a horizontal sample, gravity can be ignored. According to the Lucas-Washburn law, the imbibition length $\mathrm{L}$ is given by:

$L=\sqrt{\frac{\sigma r \cos \theta}{2 \mu_{w}}} \sqrt{t}$

This indicates that the larger the pore size, the higher the imbibition rate. Therefore, during the shale imbibition process, water preferentially fills large pores (i.e., microfractures or macropores), after which small pores (i.e., mesopores or micropores) are filled gradually. The imbibition in mesopores and micropores has a long duration (Yang et al., 2016); however, the imbibition capacity of mesopores and micropores is small, and the mass variation of the sample cannot be monitored by the current experimental testing method. Therefore, despite the continuous imbibition process, the experimental imbibition curves still quickly exhibit the transition part and plateau part. It should be mentioned that the conductivity meter is sensitive to the variation of salt concentration in the solution, which could clearly reflect the process by which salt ions in the mesopores and micropores diffuse into water. In future work, the variation in fluid electric conductivity can be adopted to complete the imbibition data and evaluate the characteristics of mesopores and micropores.

\section{Conclusions}

A series of imbibition/diffusion experiments on organic shale samples were conducted and a mathematical model based on the theoretical analysis was built to investigate the relationship between imbibition and ion diffusion. The conclusions include:

(1) Similar to the imbibition rule, the salt concentration change due to ion diffusion is proportional to the square root of time. After the imbibition front contacting with the pore wall that carries with salt ions, the salt ions dissolve and diffuse into water. As the imbibition and ions dissolution have the same movement front, the variation of electrical conductivity can be used to complement the imbibition data.

(2) During the imbibition/diffusion experiments, the imbibition/ diffusion rate show a positive correlation with the content of smectite and I/S could. No relationship is observed between illite content and imbibition/diffusion rate, indicating that illite minerals does not significantly contribute to imbibition/ diffusion rate in these clay-rich shales.

(3) Some influencing factors (i.e. porosity, surface tension, contacting area and wetting angle) have the similar effects on imbibition/diffusion rate. The porosity, surface tension and contacting area tends be positively related to imbibition/ diffusion rate; the water contact angle has a negative correlation with imbibition/diffusion rate. Other influencing factors (i.e. permeability, initial water saturation and adhesion amount of ion in unit area) have the different effects on imbibition/diffusion rate. As the permeability increases, the ion diffusion rate decreases, but the imbibition rate increases; as the initial water saturation enhances, the ion diffusion rate increases, but the imbibition rate decreases; the adhesion amount of ion in unit area are positively related to ion diffusion rate, but no relationship is found between adhesion amount of ion in unit area and imbibition rate.

\section{Acknowledgements}

The financial support of our shale research program is from the Foundation of Shale Oil and Gas Enrichment Mechanisms and Effective Development granted No. G5800-15-ZS-WX047, project funded by China Postdoctoral Science Foundation (granted No. 2016M601141), the Sinopec Group Basic Research Project granted No. P15026, the National Basic Research Program of China (973 Program) granted No.2015CB250903, the Major Program of the National Natural Science Foundation of China granted No. 51490652 and the National Science and Technology Major Project of the Ministry of Science and Technology of China granted No. 2016ZX05046-003. 


\section{References}

Asadi, M., Woodroof, R.A., Himes, R.E., 2008. Comparative study of flowback analysis using polymer concentrations and fracturing-fluid tracer methods: a field study. SPE Prod. Oper. J. 23 (2), 147-157. SPE-101614-PA.

Bennion, D.B., Thomas, F.B., 2005. Formation damage issues impacting the productivity of low permeability, low initial water saturation gas producing formations. Energy Resour. Technol. J. 127, 240-247.

Blaunch, M.E., Myers, R.R., Moore, T.R. etal. Marcellus Shale PostFracFlowbackWaters-Where is All the Salt Coming from and What are the Implications? SPE Eastern Regional Meeting, Charleston, West Virginia, USA.2009.SPE-125740-MS

Ballard, T.J., Beare, S.P., Lawless, T.A., 1994. Fundamentals of shale stabilization: water transport through shales. SPE Form. Eval. J. 9, 129-134.

Bearinger, D. Message in a Bottle. Paper URTeC-1618676 presented at the Unconventional Resources Technology Conference held in Denver, Colorado,USA 2013.

Dehghanpour, H., Lan, Q., Saeed, Y., et al., 2013. Spontaneous imbibition of brine and oil in gas shales: effect of water adsorption and resulting micro fractures. Energy fuels.. 27 (6), 3039-3049.

Facharoenphol, P., Kurtoglu, B., Kazemi, H. etal. The Effect of Osmotic Pressure on Improve Oil Recovery from Fractured Shale Formations. Presented at the SPE Unconventional Resources Conference, The Woodlands, Texas, USA, 1-3 April 2014. SPE-198998-MS.

Fan, L., Thompson, J. W., and Robinson, J. R. Understanding Gas Production Mechanism and Effectiveness of Well Stimulation in the Haynesville Shale Through Reservoir Simulation. Paper SPE 136696 presented at Canadian Unconventional Resources and International Petroleum Conference, Calgary, Alberta, Canada, 2010.

Ghanbari, E., Abbasi, M. Dehghanpour, H. Flowback Volumetric and Chemica Analysis for Evaluating Load Recovery and Its Impact on Early-Time Production. Presented at the SPE Unconventional Resources Conference-Canada held in Calgary, Alberta, Canada, 5-7 November 2013. SPE 167165-MS.

Ge, H., Yang, L., Shen, Y., et al., 2015. Experimental investigation of shale imbibition capacity and the factors influencing loss of hydraulic fracturing fluids. Petroleum Sci. 12, 636-650.

Ghanbari, E., Dehghanpour, H., 2015. Impact of rock fabric on water imbibition and salt diffusion in gas shales. Int. J. Coal Geol. 138, 55-67.

Handy, L.L., 1960. Determination of effective capillary pressure for porous media from imbibition data. Pet. Trans. AIME 219, 75-80.

Haluszczak, L.O., Rose, A.W., Kump, L.R., 2013. Geochemical evaluation of flowback brine from Marcellus gas wells in Pennsylvania, USA. Appl. Geochem. J. 28 $55-61$.

Hu, Q.H., Ewing, P.R., Dultz, S., 2012. Low pore connectivity in natural rock. J. Contam. Hydrology 133, 76-83.

Junjian, W. and Sheik, S. E.. An Investigation of Fluid Leak-off Due to Osmotic and Capillary Effects and Its Impact on Micro-Fracture Generation during Hydraulic Fracturing Stimulation of Gas Shale. Presented at the EUROPEC 2015, in Madrid Spain, 1-4 June 2015. SPE-174392-MS.

Ji, W., Song, Y., Jiang, Z., 2014. Geological controls and estimation algorithms of lacustrine shale gas adsorption capacity: a case study of the triassic strata in the southeastern ordos basin, China. Int. J. Coal Geol. 61-73.

Keller, W.D., Liovando, M., 1989. D. C.Comparative chemical compositions of aqueous extracts from representative clays. Am. Mineralogis 74, 1142-1146.

Kim, T. W. and Kovscek, A.R. The Role of Boundary Conditions and Characteristic Length on Imbibition in both Sandstones and Limestones. Presented at SPE Western North American and Rocky Mountain Joint Regional Meeting, in Denver, Colorado, USA, 16-18 April 2014. SPE-169540-MS.

King, G.E., 2012. Hydraulic fracturing 101: what every representative, environmentalist, regulator, reporter, investor, university researcher, neighbor, and engineer should know about hydraulic fracturing risk. SPE J. 64 (4), 34-42. SPE0412-0034-JPT.

Kurtoglu, B., 2013. Integrated Reservoir Characterization and Modeling in Support of Enhanced Oil Recovery for Bakken. PhD thesis. Colorado School of Mines, USA.

Lan, Q and Dehghanpour, H. Wettability of the montney tight gas formation. Presented at the SPE/CSUR Unconventional Resources Conference, Alberta, Canada, September 30, 2014

Mitchell, J.K., Moench, A., 1993. Well test analysis in naturally fissured, geothermal reservoirs with fracture skin. The 9th Stanford Geothermal Workshop. Fundamentals of Soil Behavior. Wiley, New York NY, USA.

Meng, M., Ge, H., Ji, W., et al., 2015. Investigation on the variation of shale permeability with spontaneous imbibition time: sandstones and volcanic rocks as comparative study. J. Nat. Gas Sci. Eng. (27), 1546-1554.

Murat, C., John, C.R.A., 1996. Multi-dimensional, analytical model for countercurrent water imbibition into gas-saturated matrix blocks. J. Petroleum Sci. Eng. (16), 61-69.

Novlesky, A., Kumar, A., Merkle, S. Shale Gas Modeling Workflow: from Microseismic to Simulation-a Horn River Case Study. Presented at Canadian Unconventional Resources Conference, Calgary, Alberta, Canada, 15-17 November 2011. SPE-148710-MS.

Penny, G. S., Dobkins, T. A. and Pursley, J. T. Field Study of Completion Fluids To Enhance Gas Production in the Barnett Shale. Presented at the SPE Gas Technology Symposium, Calgary, Alberta, Canada, 15-17 May 2006. SPE 100434.

Pritz, M.E, Kirby, C.S., 2011. Geochemical Investigation of Marcellus Shale Natura Gas Hydro Fracturing Waters, vol. 42. Geological Society of America Annual Meeting, p. 121 (1).

Roychaudhuri, B., Tsotisis, T., Jessen, K. 2013. An experimental investigation of spontaneous imbibition in gas shales. J. Petroleum Sci. Eng. 111, 87-97.

Treybal, R.E., 1980. Mass Transfer Operations, third ed. Mc Graw-Hill Kogakusha, Ltd.

Yang, L., Ge, H., Shen, Y., et al., 2015. Imbibition inducing tensile fractures and its influence on in-situ stress analyses: a case study of shale gas drilling. J. Natural Gas Sci. Eng. 26, 927-939.

Yang, L., Ge, H., Shi, X., et al., 2016. The effect of microstructure and rock mineralogy on water imbibition characteristics in tight reservoirs. J. Nat. Gas Sci. Eng. 34 $1-11$.

Zolfaghari, A., Noel, M., Dehghanpour, H., Bearinger, D. Understanding the origin of flowback salts: a laboratory and field study. Paper SPE-171647-MS Presented at SPE/CSUR Unconventional Resources Conference, Canada, 2014

Zolfaghari, A., Dehghanpour, H., Ghanbari, E., 2015. Fracture characterization using fowback salt-concentration transent Spe. J. $1-12$. 